\title{
OVERCONFIDENCE IN CURRENCY MARKETS
}

\author{
Thomas Oberlechner and Carol Osler
}

\begin{abstract}
This paper tests the influential hypothesis, typically attributed to Friedman (1953), that irrational traders will be driven out of financial markets by trading losses. The paper's main finding is that overconfident currency dealers are not driven out of the market. Traders with extensive experience are neither more nor less overconfident than their inexperienced colleagues. We first provide evidence that currency dealers are indeed overconfident, which is notable since they get daily trading practice and face intense financial incentives to accuracy. [Key words: Overconfidence, imperfect rationality, currency dealers, survival of imperfect rationality. JEL classifications: G14, G15, F31.]
\end{abstract}

October 14, 2009

Oberlechner: Webster University Vienna, Berchotoldgasse 1, A-1220 Vienna, Austria. Tel: 43126992930.

THOMAS_OBERLECHNER@HARVARD.EDU.

Osler: Brandeis International Business School, Brandeis University, Mailstop 32, 415 South Street, Waltham, MA 02454. Tel: (781) 736-4826.COSLER@BRANDEIS.EDU.

The authors gratefully acknowledge helpful comments from Steve Cecchetti, Blake LeBaron, Lukas Menkhoff, Dagfinn Rime, Paroma Sanyal, Robert Shiller, and Hanno Ulmer, as well as seminar participants at the Expertise in Context Conference in Berlin, the University of Hannover, Queens University Belfast, the LIEP group at Harvard University, Norges Bank, Cass Business School, and the Federal Reserve Bank of New York. Also, we acknowledge with gratitude each foreign exchange professional who took the time to fill out the survey. We gratefully acknowledge financial support for this research from the Sigmund Freud Privatstiftung and the FWF (Schroedinger Scholarship \#J2219 and \#J1955-SOZ). We take full responsibility for any errors 


\section{OVERCONFIDENCE IN CURRENCY MARKETS}

\section{INTRODUCTION}

This paper tests whether imperfect rationality survives in financial markets, an issue that is central to the debate between neoclassical and behavioral economics. According to the neoclassical view, most famously articulated by Friedman (1953), irrational traders will buy assets at high prices and sell them low prices and the ensuing trading losses will ultimately drive them out of the market. Since extensive evidence now exists for the presence of imperfect rationality in financial markets (Hirshleifer (2001) and Daniel et al. (2002) provide surveys), this argument provides an important justification for maintaining an exclusive focus on rational agents in finance: If irrational traders are ultimately forced to leave the market, then imperfect rationality should have at most a transient effect on asset prices. Nonetheless, empirical research on this question is at best rare and perhaps nonexistent. The evidence presented here suggests that one form of imperfect rationality, overconfidence, does survive in financial markets and may in fact be unaffected by trading experience.

We focus on the world's biggest market, the foreign exchange market, and on the agents that set the prices in that market, the dealers. We first provide evidence that currency dealers are indeed overconfident, on average, as logically required for this investigation. The dealers appear to be overconfident in two dimensions: they underestimate uncertainty and they overestimate their own abilities, consistent with evidence for other financial-market agents (see, for example, Glaser and Weber (2005)). We test whether overconfidence survives the rigors of the marketplace by comparing overconfidence among individuals with differing levels of experience. Our results indicate that inexperienced currency dealers are no less overconfident than experienced dealers. This robust result holds for both dimensions of overconfidence; it holds whether we measure experience by age, years of trading, or rank; and it holds for different types of dealers.

The literature suggests a number of reasons why overconfidence might survive in financial markets. Overconfident traders might make more money, either because they take on more risk (De Long et al. (1991); Hirshleifer and Luo (2001)), or because (modest) illusions of success 
enhance cognitive performance and, thus, the ability to spot profitable trading opportunities (Taylor and Brown (1988)). Alternatively, overconfidence may be necessary for survival in this market, since it helps motivate dealers to continue trading over the long haul despite inevitable trading losses (Oberlechner (2004)).

Our finding that overconfidence survives among currency traders has potential relevance for issues in both international economics and microstructure. At the intersection of those two, for example, we find the puzzle of excessive real exchange-rate volatility under floating exchange rates (Flood and Rose (1995)). Theoretical work by Odean (1998) shows that overconfident agents are likely to trade more, and connects this excess trading to excess volatility. Deaves et al. (2003) and Glaser and Weber (2007) confirm empirically that overconfident agents do trade more than others. The survival of overconfidence among currency traders could also explain the profitability of trend-following technical strategies in currency markets (Levich and Thomas (1993); Dewachter (2001); Dueker and Neely (2007)), since research shows that overconfidence can be the source of trending and trend reversals (Daniel et al. (1998)).

The forward bias puzzle - meaning the substantial average risk-adjusted returns one can expect from holding high-interest currencies - is another foreign exchange anomaly that may be related to the survival of overconfidence. Decades of effort to trace this puzzle to time-varying premiums for volatility risk have had at best mixed success (Engel (1996)). An important alternative explanation involves imperfect rationality, for which substantial indirect evidence has long existed. This evidence, which began to emerge almost three decades ago (Goodman (1979)) and has been extensively replicated (MacDonald (2000)), indicates that professional exchangerate forecasts are biased, inefficient, and incompatible across horizons. As shown in Han et al. (2008), overconfidence could be responsible for the forecasts' shortcomings as well as the overall inverse relationship between exchange-rate changes and interest differentials.

When studying the rationality of economic agents it is important to have an objective basis for choice among the infinitely many potential departures from perfect rationality. Otherwise, deviations from rationality could be tailor-made to explain each anomaly, leaving the overall hy- 
pothesis of imperfect rationality essentially impossible to disprove. Our objective basis for choice is the large body of evidence for overconfidence from the disciplines of psychology and economics. Indeed, the widespread human tendency towards overconfidence is one of the strongest findings in the psychology of judgment and cognition (Alicke et al. (2001); Lichtenstein et al. (1977)). The evidence shows that people tend to overestimate the precision of their information (Lichtenstein et al. (1977); Soll and Klayman (2004)), a tendency labeled "miscalibration" because perceived probabilities are poorly calibrated to true probabilities. People also tend to overestimate their own success (Alicke and Govorun (2005); Camerer and Lovallo (1999); Roll (1986)), a tendency often described as "hubris." According to Alicke et al. (2001), “[t]he tendency to view oneself more favorably than the average person is a staple finding in social psychology" (pp. 15-16). ${ }^{1}$ We are not alone, of course, in relying on evidence from psychology to provide a scientific basis for the study of imperfect rationality in financial markets (e.g., Barber and Odean (2000), (2001); Daniel, Hirschleifer, and Subramanyam (1998); Biais et al. (2005)).

Our sample of North American currency dealers brings several strengths to the analysis of imperfect rationality in financial markets. First, it focuses on the agents who actually set prices, rather than amateurs whose influence on the market might be limited. Second, dealers face intense financial incentives to accuracy: dealers' annual bonuses, which typically exceed $\$ 100,000$ and often exceed $\$ 1$ million, are largely determined by their personal trading profits, and the penalties for losses can include the loss of a job. Third, dealers are experts in their field who get daily practice and are provided by their employers with extensive information resources. Finally, the age and experience of our dealers vary widely: some are trainees just out of college while others have over twenty-five years of experience and have reached the rank of Treasurer.

The paper is structured as follows. Section II, which follows, summarizes the theory and evidence relevant to overconfidence and its survival in financial markets. Section III outlines the

\footnotetext{
${ }^{1}$ Other varieties of overconfidence include the illusion of control and unrealistic optimism (Biais et al. (2005); Presson and Benassi (1996); Taylor and Brown (1988)).
} 
structure of the foreign exchange market and describes our data. Section IV provides evidence for the two types of overconfidence among currency dealers. Section V provides evidence for our main result, that overconfident dealers are not driven out of the market. Section VI concludes.

\section{OVERCONFIDENCE AND THE SURVIVAL OF IMPERFECT RATIONALITY}

The existence of overconfidence in human judgment has been studied by psychologists for decades (see, for example, Oskamp (1965). Recent surveys can be found in Hoffrage (2004) and Alicke and Govorun (2005). ${ }^{2}$ The role of overconfidence has been discussed in such diverse fields as medial diagnosis (Berner and Graber (2008)), driving skills (Svenson (1981)) and recall predictions of children (Lipko, Dunlosky, and Merriman (2009)). In corporate finance, Roll (1986) proposes that corporate M\&A decisions are be motivated less by objectively expected gains than by managerial hubris, which leads to overpayments for companies. Overconfidence is also evidence in CEO and managerial decisions (e.g., Brown and Sarma (2007); John and Dimitris (2007); Malmendier and Tate (2005)), and it appears to be an important reason for excessive business entry in both experimental and real-life markets (e.g., Bolger, Pulford, and Colman (2008); Camerer and Lovallo (1999)).

In financial markets, overconfidence has been identified in experimental markets (Biais et al. (2005); Kirchler and Maciejovsky (2002)) and, through questionnaire studies, among such real-world market participants as defined contribution pension plan members (Bhandari and Deaves (2006)), pension-plan decision makers (Gort, Mei, and Siegrist (2008)), individual online brokerage investors (Glaser and Weber (2007), (2009)), and financial planners (van de Venter and Michayluk (2008)). In addition to the already-mentioned consequences of excess trading, high volatility, and momentum effects, overconfidence is a potential source of asset mis-

\footnotetext{
${ }^{2}$ While overconfidence has been called "perhaps the most robust finding in the psychology of judgment" (DeBondt and Thaler, (1995), p. 389), there is some debate as to how to measure it (Juslin and Wennerholm (1999)). For example, overconfidence can depend on the response format (see, for example, Cesarini, Sandewall, and Johannesson, (2006)). It also matters how items that measure the concept are selected (Gigerenzer, Hoffrage, and Kleinboelting, (1991); Juslin, (1994)).
} 
valuations (e.g., Daniel, Hirshleifer, and Subrahmanyam (2001)) and market bubbles (Scheinkman and Wei (2003)). Models of overconfidence have shown that miscalibration can undermine financial-market efficiency (Daniel, Hirshleifer, and Subrahmanyam (1998); Odean (1998)), an outcome confirmed experimentally by Biais et al. (2005).

By now, most economists assume that departures from rationality exist in financial markets. Nonetheless, they are often that these departures compromise financial market performance. Even if "investors are irrational ..., they [may be] met in the market by rational arbitrageurs who eliminate their influences on prices" (Shleifer (2000), p. 2). This argument is often expressed in terms of a hypothetical marginal agent: the market will achieve a rational equilibrium so long as the marginal agent is rational. ${ }^{3}$ The present study examines whether overconfidence survives among the market participants that likely serve as marginal agents. Foreign exchange dealers set the price in almost every currency transaction of meaningful size and they speculate with substantial resources at their disposal. If overconfidence survives within this group then, given limits to arbitrage, there may not be sufficient rational marginal agents for the market to achieve and maintain efficient prices.

Skepticism about the survival of imperfect rationality is often based on three apparently logical ideas: "(i) that people, through repetition, will learn their way out of biases; (ii) that experts in a field, such as traders in an investment bank, will make fewer errors; and (iii) that with more powerful incentives, the effects [of cognitive biases] disappear" (Barberis and Thaler 2003). From the relevant evidence, which is mixed, we first review the supportive evidence. Consistent with point (i), research shows that, when subjects already have substantial experience with financial-market bubbles, such bubbles are less likely to emerge in experimental settings (Smith et al. 1988). Consistent with point (ii), it has been found that certain experts - such as professional weather forecasters (Murphy and Winkler (1984)) and bridge champions (Keren (1987)) - do not display overconfidence. Likewise, List (2003) finds that overconfidence de-

\footnotetext{
${ }^{3}$ In the foreign exchange market there is substantial positive-feedback trading, in the presence of which rational arbitrageurs may actually exacerbate departures from the efficient price (De Long et al. (1990b)).
} 
creases with experience to a point where it becomes insignificant among traders of sports memorabilia and collector pins. Incentives, the focus of point (iii), can also make a difference: some aspects of preferences can change dramatically between hypothetical settings and settings with strong financial incentives (Laury and Holt (2005)).

There is also a large body of evidence, however, showing that experience, expertise, and incentives are usually insufficient to eliminate overconfidence. These studies range from early psychological experiments where miscalibration did not differ according to participants' expertise (Lichtenstein et a (1977)), to the results of experimental bidding (Allen and Dorla (2005)), to a comparison of overconfidence in judgments made by banking and trading professionals, on the one hand, and by students, on the other (Glaser, Langer, and Weber (2005)), to Chinese brokerage account data (Chen et al. (2007)). McKenzie, Liersch, and Yaniv (2008) show that information technology experts and novices are almost equally overconfident, though experts as well as novices wrongly think that experts are less overconfident. Miscalibration has been shown to influence judgment even when accuracy is financially rewarded (Fischoff et al. (1977); Sieber (1974)).

Not only is experience typically insufficient to ensure rational perception, but experience sometimes undermines rational perception. In an experiment on stock price predictions, for example, forecasting accuracy and expertise were inversely related: statisticians made more accurate forecasts than stock market experts and business students were more accurate than business teachers (Stael von Holstein (1972)). Similarly, Glaser et al. (2005) find that investment bankers are more overconfident than laymen when analyzing financial markets. While counterintuitive, this finding can be explained by a phenomenon known as "self-serving attribution," the tendency for people to take credit for successful outcomes and to blame the environment for failures (Miller and Ross (1975)). With self-serving attribution, overconfidence is not necessarily a static state, but instead it may increase with trading success, empirical support for which is reported in Jones and Nisbett (1972), Zuckerman (1979), and Statman et al. (2006). This could imply that “...it is successful traders ... who are the most overconfident. Overconfidence does not make 
traders wealthy, but the process of becoming wealthy can make traders overconfident" (Gervais and Odean (2001)).

An inverse relation between accuracy and expertise could also reflect differences in the way novices and experts process information (Adelson (1984)). Naïve decision-makers rely on fewer cues and make more conservative and constant forecasts than do experts, but the richer mental models used by experts can lead to increased scatter (i.e., variation) rather than increased accuracy (Yates et al. (1991)). Törngren and Montgomery (2004) find that stock market experts base predictions on specific but unreliable information. Likewise, the diagnoses of expert physicians are often affected by non-predictive information (Poses, Cebul et al. (1985)).

Rich mental representations can lead to higher overconfidence among experts (Mahajan (1992)). Bradley (1981) examines the influence of expertise on calibration in the context of questions that are effectively impossible to answer knowledgeably (and for which correct answers were therefore recorded no more frequently than would occur by chance). Though subjects' claimed expertise was unrelated to correctness, their willingness to admit ignorance was inversely related to claimed expertise. Indeed, many subjects that claimed expertise failed to admit any uncertainty whatsoever even when answering incorrectly. The implications of these results for the currency market, where prices are well-approximated as a random walk and the most accurate forecast is usually the no-change forecast, are fulfilled in the evidence presented below.

Even if individuals don't learn their way out of overconfidence, overconfident traders could still be driven out of the market by trading losses, since Odean (1998) shows theoretically that miscalibration should generate the mistake of excess trading and Barber and Odean (2000, 2001) show empirically that excess trading reduces profitability. Biais et al. (2005) find a direct empirical relation between miscalibration and reduced trading performance. Glaser and Weber (2007) find that hubris is also associated with excess trading. There is evidence of excess trading in currency markets (Bank for International Settlements (2007); Lyons (1996)).

Despite these arguments, the finance literature suggests a number of theoretical reasons why overconfident agents might survive in financial markets. De Long et al. (1991) argue that 
overconfident traders outperform rational traders because overconfident traders underestimate risk and hold riskier assets with higher expected returns. ${ }^{4}$ In currency markets it has been difficult to identify any relation between risk and return (Engel (1996)), though recent research identifying risk with skewness is quite promising (Brunnermeier, Nagel, and Pedersen (2008)). Kyle and Wang (1997) show that overconfident individuals involved in bilateral negotiations can survive because other participants compete less aggressively. Hirshleifer et al. (2006) show that irrational stock market investors may outperform rational investors when stock prices affect corporate investment and thus affect fundamentals, but exchange rates are unlikely to have a strong relation to corporate investment.

The survival of imperfect rationality in the foreign exchange market might more plausibly be explained by the analysis of Hirshleifer and Luo (2001), which suggests that the trading strategies of overconfident traders allow them to better exploit the mispricing caused by liquidity and noise traders. In addition, Wang (2001) examines which confidence distortions survive when the number of imperfectly rational traders is endogenous. He finds that both underconfident and extremely overconfident agents are driven out, but modestly overconfident traders ultimately dominate in markets, like foreign exchange, with high fundamental volatility (see also Bernardo and Welch (2001); Subrahmanyam (2008)).

Overconfidence may also enhance success through at least four psychological channels. First, overconfidence directly enhances mental facility (Greenwald (1980)), and might thus enable dealers to better identify profitable trading opportunities. Second, overconfidence enhances self-esteem, which in turn is associated with teamwork, organizational capabilities, leadership, and other qualities that enhance performance beyond profitability (Taylor and Brown (1988)). Third, overconfidence may inflate others' opinions about oneself (Trivers (1985)): as pointed out in Benabou and Tirole (2002, p. 872), "believing - rightly or wrongly - that one possesses certain qualities may make it easier to convince others of it."

\footnotetext{
${ }^{4}$ Though elaborated formally in the economics literature, this connection was initially suggested by psychologists (Larwood and Whittaker (1977)).
} 
Fourth, overconfidence fosters persistence, an essential trait for currency dealers (Felson 1984). Trading can be extremely stressful - active dealers, whose livelihood directly depends on their profitability, make losing trades every daily. Benabou and Tirole suggest that "confidence in his abilities and efficacy can help the individual undertake more ambitious goals and persist in the face of adversity" (2002, p. 872). Dealers concur that high confidence is critical in their profession. According to one senior trader, "When you are in the trough, you have to come out of it very quickly because if you get caught it in, it's going to affect you." According to the trading manager a top-ten foreign exchange institution, "if you are not that self-confident, you are not going to be a good trader." This highlights the possibility that currency dealers self select for overconfidence or the "sleep-well-at-night" effect: those that can handle the stress sleep well at night while those that can't handle the stress choose another occupation.

As this summary indicates, academic research in psychology and economics provides theoretical and empirical reasons to take seriously the hypothesis that imperfect rationality will be driven out of financial markets. It also provides reasons to take seriously the idea that imperfect rationality will survive and possibly even thrive in financial markets. Resolving this issue will require direct empirical tests, like those we provide below.

\section{MARKeT OVERVIEW AND DATA}

Trading in the foreign exchange market, the world's largest by any measure, averages roughly \$3.2 trillion per day (Bank for International Settlements (2007)). Wholesale trading dominates the market, as indicated by the large transaction sizes: in the electronic interbank market, for example, the minimum trade size is $\$ 1$ million. Foreign exchange dealing banks are involved in almost every significant currency trade. The interdealer market, in which banks trade with each other, by itself represents almost half of total trading (Bank for International Settlements (2007)), and the rest of trading almost invariably involves customer-bank transactions. Dealing banks stand ready to provide instant liquidity to hedge funds, mutual funds, and other asset managers, corporations that buy and sell goods internationally, central banks, and other “end-user" institutions. The dealers trade in spot, forward, futures, options, and swap contracts. 
A typical dealing room includes salespeople, interbank traders, and proprietary traders. Salespeople manage the bank's relationship with customers. Interbank dealers use the interbank market to manage inventory accumulated in customer trades and to speculate. Proprietary traders usually interbank dealers with extensive experience - focus on speculating with the bank's own funds in foreign exchange and other assets.

Our analysis of overconfidence is based on the results of a survey distributed on June 25 , 2002 to all foreign exchange dealing banks in North America. North American dealers, in aggregate, account for almost one fifth of world-wide trading (Bank for International Settlements (2007)). Of the 1,080 questionnaires sent out, 416 were completed, an overall return rate of 38.5 percent; this compares favorably with return rates of other surveys of foreign exchange professionals, which are sometimes in single digits (Cheung and Chinn (2001); Cheung, Chinn and Marsh (2004)). In aggregate, the North American dealers in our study have vast trading capacity: the sum of their daily position limits is at least $\$ 30$ billion. $^{5}$

The survey began by assessing a number of personal and professional attributes, from which we draw the following portrait of our survey participants (see Table 1). About half of them work in New York City, and most work in the spot market. As is true market-wide (Bank for International Settlements (2007)), the participants primarily trade U.S. dollars against euro and the yen, with smaller concentrations trading U.S. dollars against the Canadian dollar, British pound, and Swiss franc; a few trade other currency pairs. Though a majority of our participants trade in the interbank market, sizable portions work in sales (32 percent) or serve as proprietary traders (20 percent - note that many dealers have multiple functions). Salespeople are on average in their late thirties, a few years older than interbank and proprietary traders who are on average in their mid-thirties. Over one in five of the salespeople are female, while only one in thirteen interbank and proprietary traders are female; roughly one in ten survey respondents is female.

\footnotetext{
${ }^{5}$ The aggregate limit figure is based on dealer responses when asked to locate their position limit on a list with five ranges: \$0 -\$10 million, \$11-\$25 million, \$26-\$50 million, \$51-\$100 million, and over \$100 million.
} 
Since our study focuses on the effects of experience on overconfidence it is essential that the dealers in our sample represent a wide range of experience, and they do. The Trainees in our sample have spent just over one year on a trading floor, on average and are in their mid-twenties; the Junior Traders average four years of trading experience and are typically in their early thirties; the Senior Traders average twelve years of experience and are typically in their late thirties; the dealers in the Head Trader/Treasurers category average 17 years of experience and are typically over forty years old. Across all dealers, years of trading experience ranges up to thirty.

The use of survey data may be inevitable for analyzing overconfidence, since an individual's attitudes and states of mind can not necessarily be inferred from data on behavior. Indeed, one seemingly logical assumption about the connections between overconfidence and behavior has recently been belied by evidence. Theory suggests that excess trading stems from miscalibration (Odean (1998)), but Glaser and Weber (2007) find, when they measure attitudes, that excess trading is most closely associated with hubris. Fortunately, research based on survey data has become fairly standard in the analysis of exchange rates (e.g., Frenkel and Froot (1987); MacDonald (2000); Cheung and Chinn (2001), (2004); Menkhoff (2001)). This general acceptance reflects, in part, an acknowledgment that carefully structured surveys provide no incentive to distort the truth.

It is important to keep in mind why the rationality of experts is rarely tested in finance. Investment bankers work extremely long hours, so getting their time is a challenge in itself. The high response rate to our survey reflects close research cooperation with participating institutions and extensive follow-up efforts. Further, most finance professionals are extremely wellcompensated: established currency dealers can earn millions of dollars and base pay is in six figures. In consequence, providing them with meaningful financial payoffs is almost out of the question for academic research. Fortunately, as discussed previously, existing evidence, as well as the evidence presented below, suggests that even with financial incentives for accuracy our results would be unchanged. 


\section{EXISTENCE OF OVERCONFIDENCE}

This section sets the stage for our main result by providing evidence that currency dealers tend towards miscalibration and hubris.

\section{A. Miscalibration}

Existing evidence that people overestimate the precision of their information largely comes from experiments in which individuals provide ninety-percent confidence intervals for general knowledge questions such as "How many miles is it from Paris to Tokyo?" (Lichtenstein et al. (1977)). Under perfect rationality, ninety percent of these confidence intervals would contain the correct answer in the experiments, but that fraction is typically below half among experimental subjects (Nofsinger (2007)). Our survey took a similar approach but tailored the questions to measure financial market accuracy. Each trader was asked to "enter today's exchange rates of the Euro, the Japanese Yen, the British Pound, the Swiss Franc, and the Canadian Dollar against the U.S. Dollar. Then give your personal forecasts of these exchange rates on December 1, 2002 and on June 1, 2003. For each currency, give your actual FORECAST and the lower and the upper LIMIT of a range within which you expect these rates to be with a certainty of $90 \%$." Our main evidence in support of miscalibration comes from analyzing the confidence intervals, but we first highlight additional evidence provided by the point forecasts.

\section{Point Forecasts}

Members of the dealing community assert that traders always have "a view" concerning exchange-rate returns at our forecast horizons, and that they take these views very seriously. Accuracy matters because customers often rely on these views and good forecasting increases one's chance of becoming a proprietary trader (considered a plum job). Nonetheless, academics have found, using empirical tests, that major dollar exchange rates are well approximated as a random walk without drift, the best forecast for which is simply the current price (Meese and Rogoff (1983)). Forecasting exchange rates is thus, in the opinion of most academics, an exercise with little better than an even chance of success. Bradley's (1981) analysis, described earlier, suggests that traders will generally be unwilling to adopt the simple no-change forecast despite the magni- 
tude of the forecasting challenge, since they consider themselves to be experts. As this implies, virtually none of the point forecasts submitted by our dealers are within a few basis points of the current exchange rate. Indeed, less than four percent are within the mean absolute daily exchange-rate change (measured over the six months prior to the survey) of that current rate.

Having a view different from the current rate might be rational for dealers with special insights about exchange rates. The dealers most likely to have special insights at our forecast horizons are the proprietary traders, who regularly keep positions open for a month or more: the horizons of other traders are shorter. If dealers have special insights, the proprietary traders' forecasts should be more accurate than current rates. We calculate each proprietary trader's forecast error, meaning the proportionate difference between his/her forecast and the realized exchange rate on December 1 or June 1. We compare these to the proportionate forecast error from the nochange forecast. Since the surveys were completed on days and at times convenient to the traders, the "no-change forecast" is different in each case. The proprietary traders' root-meansquared (RMS) forecast errors exceed those of the no-change forecast in all but one of the ten separate forecast exercises (five currencies, two time horizons), and the differences are statistically significant in eight cases (Table 2, Panel A). The dealers' RMS error is usually over twice the RMS error of the no-change forecasts.

Corresponding results for salespeople and interbank traders are strikingly similar (Table 2, Panel B). Indeed, the proprietary traders' RMS forecast errors are usually statistically indistinguishable from those of other traders. Similarly, we find traders at top-tier banks are no more accurate than traders at lower-tier banks, though the former are presumably selected for excellence and paid more generously (Table 2, Panel C). Overall, these results suggest that foreign exchange dealers overvalue their insights, consistent with results in Bradley (1981).

\section{Confidence Intervals}

We now test miscalibration using traders' confidence intervals. The standard test involves comparing the share of confidence intervals that exclude the correct answer to ten percent, the true share under the null hypothesis of no overconfidence. The standard finding is that well over 
ten percent of confidence intervals exclude the correct answer, and our dealers provide no exception. For proprietary traders, 35 percent of December confidence intervals and 71 percent of June intervals exclude the realized exchange rate at the end of the forecast horizon (Table 3, Panel A). As before, proprietary traders are only slightly more accurate than their colleagues: across all traders, 39 percent of the December intervals and 76 percent of the June intervals exclude the realized rate. These results suggest that the dealers in our sample overestimate the precision of their information. Further support for this comes from the observation that the fractions for June are higher than those for December, since forecasting difficulty certainly rises with forecast horizons and psychologists find that overconfidence rises with task difficulty (e.g., Soll (1996); Pulford and Colman (1997); Dittrich et al. (2005); Lichtenstein et al. (1977)).

These results, while striking, cannot persuasively demonstrate overconfidence for two reasons. First, the point forecasts are not independent: dealers frequently discuss likely future currency movements and the commentary they read frequently includes others' forecasts. In consequence, the endpoints of each confidence interval are determined in part by the nonindependent point forecasts. Second, exchange-rate volatility over our two forecast horizons could have surprised even well-calibrated observers, since rational forecasts are not necessarily accurate ones. Suppose, for example, that dealers rationally anticipated average volatility during the forecast horizon but realized volatility turned out to be higher than average. In this case their confidence intervals would have tended to exclude realized rates, as occurs in our data, despite being rationally formed. ${ }^{6}$

For these reasons we adopt an additional approach to evaluating the rationality of dealer confidence intervals. Instead of comparing confidence intervals to realized outcomes, we compare the width of the intervals to widths implied by rational volatility forecasts. These rational

\footnotetext{
${ }^{6}$ Multiple tests are appropriate because more pronounced overconfidence has been found with subjective confidence intervals (Klayman, Soll et al. 1999). West and Stanovich (1997) find both substantial domain specificity in confidence judgments and general overconfidence mechanisms.
} 
forecasts are calculated based on GARCH models of exchange-rate returns. ${ }^{7}$ Since the dealers completed the survey sometime between July and October of 2002, the volatility forecast should vary according to the specific month in which the forecast was compiled. For each of our five exchange rates we create forecasts at horizons of $1,2,3,4,7,8,9$, and 10 months, where each sample ends in the associated survey-completion month, using historical non-overlapping returns. This way each end-of-sample conditional variance estimate is our time-horizon-specific rational forecast for the conditional variance of that exchange rate over the appropriate forecast horizon. From these we calculate the associated ninety-percent confidence intervals that serve as our objective basis for comparison with the dealers' own intervals using the fact that the ninetypercent confidence interval for a normal distribution equals approximately 3.29 times the standard deviation. An example may be helpful: to find an objective benchmark for the December confidence intervals completed in July, we estimated a GARCH model of non-overlapping fourmonth returns where the last observation was July 2002; the benchmark interval width was 3.29 times the estimated July 2002 standard deviation.

If our dealers are well-calibrated then about half of their confidence intervals should be wider than the GARCH benchmark. Instead, almost all the confidence intervals are narrower than the benchmark (Table 3, Panel B). For the proprietary traders' December forecasts, between 88.9 and 99.4 percent of the confidence intervals are too narrow; for their June forecasts, between 97.8 and 99.7 percent of the confidence intervals are too narrow. Results for all traders are similar, as are results for traders at top-tier institutions (Table 3, Panel C). Our qualitative conclusion is also unchanged if the unconditional distribution of returns is used to generate confidence intervals, rather than the conditional distribution. ${ }^{8}$

\footnotetext{
${ }^{7}$ The data, which come from Datastream, begin in 1970 for EUR, GBP, and CHF, and in 1978 for JPY and CAD. In every case we first tried a GARCH(1,1) model. This converged (in Stata) in 32 of 40 cases. If this failed, we tried a $\operatorname{GARCH}(2,2)$ model (converged in five cases), a $\operatorname{GARCH}(3,3)$ model (converged in two cases), and finally an ARCH(1) model.

${ }^{8}$ These results, unreported to save space, are available upon request.
} 
Though these figures seem high, it is critical to evaluate their statistical significance. We take the null hypothesis to be rationality and we view each trader's interval as the outcome of a Bernoulli trial in which each confidence interval could be too wide or too narrow with equal probability. For each currency, month of survey completion, and forecast date (December, June) the number of confidence intervals that are too narrow should thus have a binomial distribution with $p=0.5$ and $n=$ the number of responding traders (e.g., $n=262$ for December 1 forecasts for the euro submitted in July). Since our sample sizes are reasonably large and $p$ is not extreme, the distribution is well approximated by the normal distribution with mean $n p$ and variance $n p(1-p)$.

This bootstrap exercise shows that our results are strongly statistically significant. Marginal significance levels are below 0.0001 in almost every case. Note that this test is biased in favor of the hypothesis of rationality because our estimated "objective" confidence intervals will be a bit too narrow. This follows from our assumption that forecasts are compiled at the end of each month, which means that the true forecast horizons, and thus the true confidence intervals, will in most cases exceed the forecast horizons from which we calculate confidence intervals.

These tests assume that each survey participant decides the width of his confidence intervals independently from other participants, which seems reasonable because market participants rarely discuss confidence interval widths. Nonetheless, we next show that our conclusions hold even if the interval widths are not generated independently. To do this we bootstrap the appropriate confidence intervals under the null hypothesis that in each period $t$, dealer $j$ 's confidence interval width for currency $c$ at horizon $h, C I_{t c h}^{j}$, is determined as the sum of a market-wide component, $C I^{M}{ }_{t c h}$, and an idiosyncratic component, $\tilde{d}_{t c h}^{j} \cdot C I_{t c h}^{j}=C I_{t c h}^{M}+d_{t c h}^{j}$.

To determine the market-wide components we sample (with replacement) 1,000 times from our GARCH model's fitted values of volatility to create a series of variances, $V_{t c h}^{M}$, and for each variance we calculate the associated ninety-percent confidence interval width, $C I^{M}{ }_{t c h}=$ $3.29 \sqrt{V_{t c h}^{M}}$. These serve as the common component of everyone's confidence-interval width for period $t$. To create the simulated individual confidence interval widths, $C I_{t c h}^{j}$, we add idiosyncrat- 
ic width terms, $\tilde{d}_{t c h}^{j}$, found by sampling (with replacement) from the original differences between each dealer's (absolute) width and the mean (absolute) width across all dealers submitting forecasts in a given month: $d_{c h}^{i}=w_{i d t h}^{i}{ }_{c h}$-meanwidth ${ }_{c h}$. For each of the 1,000 periods we create $n$ of these individual confidence-interval widths, where $n$ again corresponds to the number of dealers submitting confidence intervals for currency $c$ for the December or June forecast date in a given month. We also create a series of 1,000 "true" variances, $V^{T}{ }_{t c h}$, and associated rational confidence interval widths, $C I^{T}{ }_{t c h}=3.29 \sqrt{V_{t c h}^{T}}$, by sampling a second time (again with replacement) from the GARCH model's fitted volatilities.

For each of the 1,000 periods, we calculate the share of simulated individual confidence intervals that are narrower than the "true" interval width, $\mathrm{CI}^{T}{ }_{t c h}$. The distribution of these shares represents the true distribution of shares under the null hypothesis that individuals' estimated confidence interval widths are unbiased but otherwise correlated with each other. We note that this test implicitly assumes that estimated and actual confidence interval widths are uncorrelated, which we accept because it favors the hypothesis of no overconfidence and because anything else would necessarily involve arbitrary assumptions that would make it difficult to interpret the results. We carry out this test for surveys completed in July and September, since few were completed in August and October.

For the December forecasts the tests indicate that our survey participants tended to be significantly overconfident (Table 4): we can reject the null hypothesis at the five percent level or better for eight of the ten tests (five currencies, two forecast horizons each), and we can reject it at the ten percent level in one additional test. For the June forecasts we reject the null at standard significance levels in four of the ten cases and in the other cases our failure to reject is often due to low power. For example, we cannot statistically reject the joint null for Euro confidence intervals for June forecasts submitted in September, even though 100 percent of the dealers' own intervals were narrower than the GARCH measure.

This section has provided three types of evidence indicating that currency traders tend to overestimate the precision of their information. When forecasting exchange rates they choose not 
to rely on the current rate, even though that rate would be more accurate than their own forecasts; their ninety-percent confidence intervals exclude the realized exchange rate in far more than ten percent of cases; and their ninety-percent confidence intervals tend to be wider than "rational" confidence intervals, meaning those based on econometric forecasts of conditional volatility. We next provide evidence that dealers also tend to overrate their personal success.

\section{B. Hubris}

Our tests for hubris are based on responses to the following question: "How successful do you see yourself as a foreign exchange trader?" The top rank of 7 was assigned to "Much more successful than other foreign exchange traders;" the bottom rank of 1 was assigned to "Much less successful than other foreign exchange traders"; "Average" was assigned to the middle rank of 4. All categories of the seven-step rating scale were individually labeled.

We also asked the participants' immediate superiors (i.e., head traders or chief dealers) to rate their subordinates. The superiors were specifically instructed to compare individuals to others with similar responsibilities at the same institutional rank, since such specificity is shown in the organizational literature to increase discriminative ratings and to reduce judgment errors among supervisors (Locklear, Granger, and Veres (1989)). ${ }^{9}$ The superiors rated their subordinates along three dimensions: "overall contribution to the organization," "trading profits," and "trading potential." Traders' overall contributions to the organization were comprehensively defined to include trading profits and broader factors such as the support of other traders and the completion of tasks for the whole group (Borman and Motowidlo (1993)). Overall Contribution thus matches the overall success rating requested of the traders themselves. Trading Profits is self-explanatory. Trading Potential was defined as the degree to which traders have the personal making of successful traders in their trading area; head traders were specifically instructed to separate trading potential from realized profits. The three ratings are highly correlated, with bilateral correlation coefficients ranging from 0.58 to 0.72 .

\footnotetext{
${ }^{9}$ For example, without position-specific standards, supervisors may show an unwanted tendency to rate workers better the higher their rank (Brandstätter 1970).
} 
Our currency market professionals give themselves an average rank of 5.06, or "better than average," with standard error of 0.05 (Table 5). This suggests overconfidence, as does the related observation that three quarters of traders perceive themselves as more successful than average, a fraction that is, of course, statistically unlikely to be accurate. Indeed, roughly fourteen times as many dealers perceive themselves above average as perceive themselves below average.

Of course, most of our dealers work at top tier institutions, where trading skill could well $b e$ above average. If this explains our result, then traders at lower tier institutions should generally rate themselves below average. However, the fraction of traders at lower tier banks rating themselves above average is only a bit lower than the fraction at top tier banks. As noted earlier, this is consistent with existing evidence. Svenson (1981), for example, finds that 93 percent of participating U.S. college students consider themselves better-than-average as a driver. The result is notable because currency dealers potentially serve as the marginal agent in the foreign exchange market and because they have strong incentives to overcome perceptual biases.

To evaluate the statistical significance of these results we undertake a bootstrap test of the null hypothesis of no hubris, taking the superiors' ratings to represent the true distribution of ratings within rank and responsibility classes. ${ }^{10}$ This evaluation is necessarily limited, since only two of the twelve rank-responsibility combinations include sufficient individuals to generate a meaningfully powerful test. These two categories are senior interbank traders, with 78 individuals, and senior salespeople, with 94 individuals. Fortunately, these two groups together include 70 percent of the total sample with matched ratings.

Our goal is to calculate the likelihood of observing a given fraction of self-proclaimed above-average traders within a given rank-responsibility category under the null hypothesis of no overconfidence. We create 1,000 sets of $k$ ratings, where $k$ is the number of individuals in that rank-responsibility category with ratings from their superior as well as themselves. Each rating is drawn at random (with replacement) from the sample of superiors' ratings. For each set of simu-

\footnotetext{
${ }^{10}$ Note: The test does not assume that superiors correctly rated individual traders. It makes the less restrictive assumption that the distribution of ratings by superiors accurately portrays the distribution of true ratings.
} 
lated ratings we calculate the fraction of above-average ratings. For each rating category this gives us 1,000 fractions, one from each set, the distribution of which we compare with the corresponding fraction from our $k$ survey participants in that category. If an observed fraction is more extreme than 95 percent of the 1,000 corresponding fractions in the simulated data, we reject the null of no hubris. Note that the tests are biased towards accepting the null, since the supervisors themselves tended to rate their subordinates better-than-average. Average supervisors' ratings (standard errors) are $4.6(0.09), 4.5(0.09)$, and 4.9 (0.08) for the Overall Contribution, Trading Profits, and Trading Potential dimensions, respectively.

The tests reject the null hypothesis of no overconfidence with great statistical significance (Table 6). In our baseline test, which uses the Overall Contribution rating by superiors, none of the 1,000 sets of simulated ratings had a share of above-average senior interbank traders as high as the observed share of 77.7; indeed, the highest simulated share was only 66.2. Similarly, not one of the sets of simulated ratings had a share of below-average interbank traders as low as the observed fraction of 5.6; the lowest simulated share was 6.5. Our conclusions are not changed if the superiors' ratings for Trading Profitability or Trading Potential replace their ratings for Overall Contribution.

\section{Survival OF OVERCONFIDENCE}

Having presented evidence that foreign exchange dealers tend to be overconfident, we can now examine the paper's central question: Is overconfidence driven out of the foreign exchange market? This could occur if individual dealers become correctly calibrated over time, given frequent feedback and strong incentives for accuracy. It could alternatively occur if overconfident dealers are fired or choose another profession, so that only rational dealers remain in the profession. The evidence presented in this section indicates that overconfident dealers are not driven out of the market.

To examine this issue we need measures of each individual's overconfidence. Our measure of miscalibration focuses on the extent to which a dealer's confidence intervals fall short of their value under rationality, taking the rational value to be the width calculated from our 
GARCH analysis. We first calculate the ratio between the width of each confidence interval and the appropriate width. As before, since the dealers submitted their surveys in either July, August, September, or October so we have four horizons each for the December and January forecast. For dealer $i$, currency $c$, and forecast horizon $h$, this is ratio is: $R_{c h}^{i} \equiv w_{c h}^{i} / w^{G}{ }_{c h}$, where $w_{c h}^{i}$ is the dealer's chosen width and $w_{c h}^{G}$ is the GARCH-based width. Each dealer provided up to ten confidence intervals (five currencies each for the December and June forecasts), so we take the average of the ratios, $R^{i}$. Dealer $i$ 's miscalibration, $M^{i}$, is then defined as the gap between unity and this average: $M^{i} \equiv 1-R^{i}$. For well-calibrated individuals this measure is zero; for overconfident individuals it ranges upwards to a maximum of one. ${ }^{11}$

To measure each trader's hubris we compare the trader's rating of his/her own performance, $P_{\text {Own }}^{i}$, with the superior's Overall Contribution rating, $P_{\text {Sup }}^{i}: H^{i} \equiv P_{\text {Own }}^{i}-P_{\text {Ssup } .}^{i 2}$ For agents who are not overconfident this will be zero; like miscalibration, $H^{i}$ rises with overconfidence. Note that this measure is not available for lower-tier banks because superiors' ratings were only solicited from top-tier banks.

To ensure robustness we measure experience in three ways: years spent trading, age, and rank. Years spent trading is divided into three categories, with roughly equal numbers of dealers in each: 0-8 years, 9-14 years, and 15 or more years. Age is divided into four categories: 30 and under, 31-35, 36-40, and over forty. Rank is divided into three categories: Trainees and Junior Traders, Senior Traders, and Head Dealers/Treasurers.

We pause briefly to describe some properties of the two overconfidence measures. In our data, women tend to display less overconfidence by both measures; the same can be said for salespersons relative to other traders. Since women are disproportionately represented among

\footnotetext{
${ }^{11}$ Note that the correlation between the dealers' average December and average June ratios is a strong 0.79, which suggests there is little loss of information when combining intervals.

12 This measure effectively assumes that superior's ratings are more objectively accurate than those of their subordinates. Indeed, since the ratings of superiors and their subordinates are almost uncorrelated, at most one of them can reasonably be assumed to be correlated with "objective truth." We choose superiors' ratings for this role since their average rating is closer to the theoretical mean of 4.0. Though this seems the best available measure of overconfidence, we are aware that superiors will never be perfectly accurate in assessing their subordinates.
} 
foreign exchange salespeople, one might guess that the pattern for women explains the pattern for salespeople, but the differences in overconfidentce between salespeople and others appear to be sustained after controlling for gender. We note in passing that the influence of gender on overconfidence remains uncertain: Deaves et al. (2003), for example, find no influence.

It might also be natural to assume that miscalibration and hubris are closely related. Indeed, Gervais and Odean (2001) describe how hubris could be the source of miscalibration. Nonetheless, the correlation coefficient between miscalibration and hubris is an economically small 0.15 , though statistically significant. A weak relation between these two dimensions of overconfidence is consistent with results from other relevant studies (Deaves et al. (2003); Régner et al. (2004); Glaser and Weber (2007)).

Our analysis of the survival of overconfidence is organized around two testable implications of Friedman's famous assertion that imperfect rationality is driven out of markets (1953): Hypothesis 1, Absolute Rationality: Dealers with the most experience are not overconfident at all. Hypothesis 2, Relative Rationality: Dealers overconfidence declines with experience, so experienced dealers are less overconfident than their junior colleagues.

\section{A. Absolute Rationality: Are The Most Experienced Dealers Overconfident?}

If imperfect rationality is driven out of the market, the most experienced traders will not be overconfident at all. Table 7, which reports the averages of our two overconfidence measures for dealers in different experience categories, provides no support for this hypothesis.

In Table 7A, which focuses on miscalibration, we find that overconfidence is statistically significant among the most experienced dealers no matter how we measure experience. Among dealers with fifteen or more years of trading experience, confidence intervals are about half as large as they should be if dealers were well-calibrated, with $t$-statistic of 9.9. Confidence intervals among dealers over 40 years old are 46 percent smaller than they should be, with $t$-statistic of 24.4, and among Head Traders/Treasurers they are over 60 percent too small, with $t$-statistic of 4.5 . 
Hubris is also strong, both economically and statistically, for experienced dealers. For dealers with fifteen or more years of experience, hubris averages 0.65 , with $t$-statistic 2.2 . This represents a substantial distortion of their performance ratings, as it covers over a quarter of the gap between the superior's average performance rating for this group, which is 4.5 , and the highest possible rating, which is seven. Average hubris is 0.46 for dealers over 40 years old, with $t$ statistic 2.1, which implies that this group inflates their performance rating almost 20 percent of the way towards ideal performance, on average. Average hubris is 1.13 for Head Traders and Treasurers, which implies these individuals inflated their performance rating almost half-way to ideal performance.

As discussed in Section III, the incentives to overcome miscalibration are strongest for proprietary traders, so this group provides a particularly strong test of whether experienced declines are overconfident. However, the miscalibration and hubris measures for this group provide no evidence for dealer rationality. Among the most experienced proprietary traders, both miscalibration and hubris are statistically and economically significant. (Note that, to conserve statistical power, we create fewer age categories when analyzing proprietary traders; we also do not use "rank" to measure experience since almost all proprietary traders have the rank of Senior Trader or higher.)

We also examine miscalibration among dealers at top-tier banks (as noted earlier, our hubris measures already apply only to top-tier banks). These dealers likely have greater influence over market prices than other dealers because they have larger position limits and more customers. In effect, the marginal or price-setting agents in the foreign exchange market are more likely to work at large banks than small banks. A comparison of Table 7D, which focuses on top-tier banks, and Table 7A, which considers all traders, suggests no difference between dealer miscalibration at top- and lower-tier banks. Our conclusion that experienced dealers are positively overconfident is also sustained if we focus exclusively on the currencies that dealers trade most actively. ${ }^{13}$

\footnotetext{
${ }^{13}$ Results of these robustness tests are available upon request.
} 


\section{B. Relative Rationality: Does Overconfidence Decline With Experience?}

Even if overconfidence doesn't completely disappear with experience it could still be modrated by experience. To examine whether this actually occurs compare overconfidence across dealers with varying experience. Table 7A shows that miscalibration varies little with experience. When experience is measured in terms of years spent trading, measured miscalibration is 0.46 for the group with least experience, 0.47 for the group with intermediate experience, and 0.50 for dealers who have been trading 15 years or longer. Even though the slight differences across these measures are not statistically significant, we note for later reference that the direction of change runs counter to the hypothesis that irrational traders are driven out of financial markets. When experience is measured by age, the miscalibration point estimates vary nonmonotonically with experience - they average 0.46 for the two youngest groups, 0.51 for traders in their late 30s, and then once again 0.46 for traders over forty - though these differences, too, are insignificant. When experience is measured by rank, miscalibration varies most widely, but even here it only ranges from 0.46 to 0.62 . Here again, measured overconfidence is highest for the most experienced dealers though the differences across groups are insignificant.

As shown in Table 7B, the hubris measures provide even less support for the hypothesis that overconfidence declines with experience; indeed, this evidence suggests weakly that hubris rises with experience. This is not entirely surprising since, as discussed in Section I, there exists substantial evidence for the hypothesis that overconfidence gets stronger with experience, a result that is especially strong when correct answers are not much more likely than by chance, as in the foreign exchange market. When experience is measured by years spent trading, average hubris is 0.50 for the least experienced traders, 0.47 for traders with intermediate experience, and 0.65 for traders with the most experience. Though this suggests that hubris rises with experience, the differences across groups are again insignificant. When experience is measured by age or rank, however, the evidence that hubris rises with experience is a bit stronger. For both these measures of experience, average hubris is statistically insignificant, and lowest, for the least experienced traders while it is significant for all other groups. When experience is measured by 
age, average hubris is only 0.23 for those in their twenties but it ranges from 0.46 to 0.64 for older traders. When experience is measured by rank, average hubris is 0.41 for Trainees and Junior Traders, 0.45 for Senior Traders, and 1.13 for Head Traders/Treasurers. The evidence for the hypothesis that hubris rises with experience is weakened, however, by the fact that differences across hubris across experience categories remain insignificant.

The strongest evidence that experience and incentives fail to moderate overconfidence comes from a comparison of proprietary traders, as a group, with salespeople and interbank traders. As shown in the top panel of Table 7C, proprietary traders are significantly more miscalibrated and hubristic than salespeople, though salespeople forecast less frequently and are rewarded only indirectly for accuracy. Among proprietary traders with different levels of experience, miscalibration and hubris averages do not vary widely across experience categories and differences between experience categories are insignificant. The conclusion that overconfidence is not moderated by experience likewise gains no support from an analysis of dealers at top-tier banks.

\section{Additional Tests}

Since the results in Table 7 could conceivably be driven by a few extremely overconfident individuals, we present two additional sets of figures. These indicate that miscalibration and hubris are widespread. These tests, like our previous tests, provide no support for the hypothesis that imperfectly rationality is driven out of financial markets.

Table 8A shows the share of dealers whose confidence intervals are too narrow, with the "correct" width again taken to be the width associated with the conditional volatility estimates. Even for the most experienced dealers, the vast majority of confidence intervals are too narrow. Further, the share of intervals that are too narrow is, in essence, insensitive to the dealers' level of experience. This conclusion holds for all three approaches to measuring of experience and, though not shown in the table, it also holds if we focus exclusively on the currencies that dealers most actively trade. 
Table $8 \mathrm{~B}$ shows the fraction of dealers rating themselves above and below average, along with the fraction of dealers rated above and below average by their superiors, disaggregated according to experience as measured by years of trading experience, age, or rank. The fraction of experienced dealers rating themselves above average ranges from 67 percent to 81 percent and is substantially above the corresponding fraction from their superiors in almost every case. For example, 73 percent of dealers with over twenty years of experience rated themselves above average. This might seem potentially reasonable, since these dealers have clearly thrived in this market, but according to their superiors only half of these dealers were actually above average. Thus the tendency to overrate one's-self appears to characterize even the most seasoned currency dealers. Further, the table provides no evidence that this tendency abates as dealers gain experience.

The results of this section suggest consistently that imperfect rationality is not driven out of currency markets. Despite many years of trading and strong incentives to accuracy, experienced dealers still tend to overestimate the precision of their information and still tend to overestimate their own abilities. Further, these tendencies do not appear decline as dealers gain experience.

\section{CONCLUding ObSERVATIONS}

This paper tests whether overconfident traders are driven out of the foreign exchange market. Friedman famously claimed that imperfectly rational traders will be driven out of the market by trading losses (1953), a claim that has been influential because it suggests that imperfect rationality can be disregarded and we can reasonably assume efficient markets. Nonetheless, the claim has rarely, if ever, been tested. We focus on a well-documented form of imperfect rationality, overconfidence, and test its survival among the traders who set prices in the world's largest market.

We set the stage for our analysis by providing evidence that currency dealers, like most people, display two types of overconfidence: they tend to overestimate the precision of their information (miscalibration) and they tend to overestimate their professional success (hubris). We 
then compare the overconfidence of foreign exchange dealers with various degrees of experience. The results indicate that even the most experienced dealers are strongly overconfident and that overconfidence is not moderated by experience or incentives.

These conclusions hold for both types of overconfidence; they hold regardless of whether we measure experience by years spent trading, age, or professional rank; they hold for proprietary traders, the ones with the strongest incentives to accuracy, as well as other traders; and they hold for the subset of our dealers who work at the most active dealing banks. The survival of overconfidence among influential financial-market participants with strong incentives to accuracy is not consistent with the assumptions of perfect rationality and efficient markets. Nonetheless, our results are consistent with much evidence from economics and psychology.

Future research could constructively examine the mechanism(s) through which dealer overconfidence survives. Among the many possibilities worth exploring, we highlight three: Overconfidence, by leading others to have inflated opinions of one's success, might increase one's likelihood of promotion within an organization; overconfidence, by enhancing cognitive facility, might enhance dealers' ability to identify profitable trading opportunities; overconfidence, by fostering persistence and a tolerance for adversity, might enable dealers to sustain a career with such intense competition and frequent setbacks. 


\section{REFERENCES}

Adelson, B. When novices surpass experts: The difficulty of a task may increase with expertise. Journal of Experimental Psychology: Learning, Memory, and Cognition 10 (1984): 483495.

Alicke, Mark D., Debbie S. Vredenburg, Matthew Hiatt, and Olesya Govorun. The 'better than myself effect,' Motivation and Emotion 25 (2001): 7-22.

Alicke, M. D., and O. Govorun. The better-than-average effect. In M. D. Alicke, D. A. Dunning and J. I. Krueger (Eds.), The Self in Social Judgment. (Psychology Press, 2005): 85-106.

Allen, W. D., and A. E. Dorla. Bidding and overconfidence in experimental financial markets. The Journal of Behavioral Finance, 6 (2005): 108.

Bank for International Settlements. Triennial Central Bank Survey of Foreign exchange and Derivatives Market Activity in 2007 (Basle: 2007).

Barber, B. M. and T. Odean. Trading is hazardous to your wealth: The common stock investment performance of individual investors. Journal of Finance 55 (2000): 773-806.

Barber, B. M. and T. Odean. Boys will be boys: Gender, overconfidence, and common stock investment. The Quarterly Journal of Economics 116 (2001): 261-292.

Barberis, Nicholas, and Richard Thaler. A survey of behavioral finance, Handbook of the Economics of Finance, G.M. Constantinides, M. Harris, and R. Stulz Eds (Elsevier Science: 2003): 1051-1121.

Benabou, R., and J. Tirole. Self-Confidence and Personal Motivation. Quarterly Journal of Economics, 117 (2002): 871.

Bernardo, A. E., and I. Welch. On the Evolution of Overconfidence and Entrepreneurs. Journal of Economics and Management Strategy, 10 (2001): 301-330.

Berner, E. S., and M.L. Graber, Overconfidence as a cause of diagnostic error in medicine, American Journal of Medicine 121 (2008): S2-S23.

Bhandari, G., and R. Deaves. The demographics of overconfidence. Journal of Behavioral Finance, 7 (2006): 5-11.

Biais, Bruno, Denis Hilton, Karine Mazurier and Sebastien Pouget. Judgmental overconfidence, self-monitoring, and trading performance in an experimental asset market," Review of Economic Studies 72 (2005): 287-312.

Bolger, F., Pulford, B.-D., and A-M. Colman. Market entry decisions: Effects of absolute and relative confidence, Experimental Psychology 55 (2008): 113-120.

Borman, W. C. and S. J. Motowidlo. Expanding the criterion domain to include elements of contextual performance. Personnel selection in organizations. N. Schmidt and W. C. Borman (San Francisco, Jossey-Bass: 1993): 71-98.

Bradley, J. V. Overconfidence in Ignorant Experts. Bulletin of the Psychonomic Society 17 (1981).

Brandstätter, H.. Die Beurteilung von Mitarbeitern. In: Mayer, A., and Herwing, B.: Handbuch für Psychologie, Volume 9, Betriebspsychologie (Verlag für Psychologie: Hogrefe 1970) : 668-734. 
Brown, R., and N. Sarma. CEO overconfidence, CEO dominance and corporate acquisitions. Journal of Economics \& Business, 59 (2007): 358-379.

Brunnermeier, Markus, Stefan Nagel, and Lasse Pedersen. Carry Trades and Currency Crashes. NBER Working Paper 14,473 (2008).

Camerer, C., and D. A. N. Lovallo. Overconfidence and excess entry: An experimental approach. American Economic Review, 89 (1999): 306-318.

Cesarini, D., Sandewall, Â. r., and M. Johannesson. Confidence interval estimation tasks and the economics of overconfidence. Journal of Economic Behavior \& Organization, 61 (2006): 453-470.

Chen, G., K. A. Kim, J. R. Nofsinger, and O.M. Rui. Trading performance, disposition effect, overconfidence, representativeness bias, and experience of emerging market investors. Journal of Behavioral Decision Making, 20 (2007): 425-451.

Cheung, Yin-Wong, and Menzie David Chinn, Currency traders and exchange-rate dynamics: A survey of the U.S. market, Journal of International Money and Finance 20 (2001): 439-471.

Cheung, Yin-Wong, Menzie D. Chinn, and Ian Marsh, How do U.K.-based foreign exchange dealers think their market operates? International Journal of Finance and Economics 9 (2004): 289-306.

Daniel, Kent D., David Hirshleifer, and Avanidhar Subrahmanyam. Investor psychology and security market under- and overreactions, Journal of Finance 53 (1998): 1839-85. of Finance 56 (2001): 921-965.

Overconfidence, arbitrage, and equilibrium asset pricing, Journal

Daniel, Kent D., David Hirshleifer, and Siew Hong Teoh. Investor psychology in capital markets: Evidence and policy implications, Journal of Monetary Economics 49 (2002): 139-209.

Deaves, Richard, Erik Lüders, and Guo Ying Luo. "An Experimental Test of the Impact of Overconfidence and Gender on Trading Activity." Working paper, McMaster University (2003).

De Bondt, Werner F. M., and Robert H. Thaler. Does the stock market overreact? Journal of Finance 40 (1985): 793-808.

De Long, J. B., A. Shleifer, L. H. Summers, R. J. Waldmann. Positive feedback investment strategies and destabilizing rational speculation. Journal of Finance 45 (1990): 379-395.

Business 64 (1991): 1-19. The survival of noise traders in financial markets, Journal of

Dewachter, Hans. Can Markov switching models replicate chartist profits in the foreign exchange market? Journal of International Money and Finance 20 (2001): 25-41.

Dittrich, D. A. V., Guth, W., and B. Maciejovsky. Overconfidence in investment decisions: An experimental approach. European Journal of Finance, 11 (2005): 471.

Dueker, Michale, and Christopher Neely. Can Markov switching models predict excess foreign exchange returns? Journal of Banking and Finance 31 (2007): 279-96.

Engel, Charles. The forward discount anomaly and the risk premium: A survey of recent evidence. Journal of Empirical Finance 3 (1996): 123-192. 
Felson, R.B. The effect of self-appraisals of ability on academic performance. Journal of Personality and Social Psychology 47 (1984): 944-952.

Fischhoff, Baruch, Paul Slovic and Sarah Lichtenstein. Knowing with certainty: The appropriateness of extreme confidence. Journal of Experimental Psychology: Human Perception and Performance 3 (1977): 552-56.

Flood, Robert P., and Andrew K. Rose. Fixing exchange rates: A virtual quest for fundamentals, Journal of Monetary Economics 36 (1995): 3-37.

Friedman, Milton. Essays in Positive Economics (University of Chicago Press, Chicago: 1953).

Gervais, S., and T. Odean. Learning to be overconfident, Review of Financial Studies 14 (2001):1-27.

Glaser, M., Thomas Langer, and M. Weber. Overconfidence of Professionals and Laymen: Individual Differences Within and Between Tasks? Working paper (2005).

Glaser, M., and M. Weber. Overconfidence and trading volume. Geneva Risk and Insurance Review, 32 (2007): 1-36.

12 (2009): 1-31.

Which past returns affect trading volume? Journal of Financial Markets

Goodman, Stephen H. Foreign exchange rate forecasting techniques: Implications for business and policy, Journal of Finance 34 (1979): 415-427.

Gort, C., Mei, W., and M. Siegrist. Are pension fund managers overconfident? Journal of Behavioral Finance, 9 (2008): 163-170.

Greenwald, A.G. The totalitarian ego: Fabrication and revision of personal history, American Psychologist 35 (1980): 603-618.

Han, Bing, David Hirshleifer, and Tracy Yue Wang. Investor overconfidence and the forward discount puzzle. SSRN http://papers.ssrn.com/sol3/papers.cfm?abstract_id=841038 (2008).

Hirshleifer, David. Investor psychology and asset pricing, Journal of Finance 56 (2001): 15331597.

Hirshleifer, D., and Luo, G. Y. On the survival of overconfident traders in a competitive securities market, Journal of Financial Markets 4 (2001): 73-84.

Hirshleifer, D., Subrahmanyam, A., and Titman, S.. Feedback and the success of irrational investors. Journal of Financial Economics, 81 (2006): 311-338.

Hoffrage, U. Overconfidence. In R. Pohl (Ed.), Cognitive illusions: A handbook on fallacies and biases in thinking, judgement and memory: (Psychology Press: 2004): 235-254.

John, A. D., and P. Dimitris. Acquisitions, overconfident managers and self-attribution bias. European Financial Management 13 (2007): 531.

Jones, E.E., and R.E. Nisbett. "The actor and the observer: Divergent perceptions of the causes of behavior," in E.E. Jones, D.E. Kanouse, H.H.Kelley, R.E. Nisbett, S. Valins, and B. Weiner (Eds.), Attribution: Perceiving the Causes of Behavior (General Learning Press, Morristown, NJ: 1972). 
Juslin, P. The overconfidence phenomenon as a consequence of informal experimenter-guided selection of almanac items. Organizational Behavior \& Human Decision Processes, 57 (1994): 226-246.

Juslin, P., and P. Wennerholm, P. Format dependence in subjective probability calibration. Journal of Experimental Psychology / Learning, Memory \& Cognition, 25 (1999): 1038.

Keren, G. Facing uncertainty in the game of bridge: A calibration study. Organizational Behavior and Human Decision Processes, 39 (1987): 98-114.

Kirchler, Erich, and Boris Maciejovsky. Simultaneous over- and underconfidence: Evidence from experimental asset markets, Journal of Risk and Uncertainty 25 (2002): 65-85.

Klayman, Joshua, Jack B. Soll, C. González-Vallejo. Overconfidence: It depends on how, what, and whom you ask. Organizational Behavior and Human Decision Processes 79 (1999): 216-247.

Kyle, Albert S., and F. Albert Wang. Speculation duopoly with agreement to disagree: Can overconfidence survive the market test? Journal of Finance 52 (1997): 2073-2090.

Larwood, L., and W. Whittaker. Managerial myopia: Self-serving biases in organizational planning, Journal of Applied Psychology 62 (1977): 194-198.

Laury, Susan K., and Charles A. Holt. Risk aversion and incentive effects: New data without order effects. American Economic Review 95 (2005): 902-904.

Levich, R, and Thomas, L. The significance of technical trading profits in the foreign exchange market: A bootstrap approach. Journal of International Money and Finance 12 (1993): 451474.

Lichtenstein, Sarah, Baruch Fischhoff, and L. D. Phillips. The calibration of probabilities: The state of the art. In H. Jungermann and G. deZoeuw (Eds.), Decision Making and Change in Human Affairs (D. Reidel, Amsterdam: 1977).

Lipko, A. R., J. Dunlosky, and W.E. Merriman. Persistent overconfidence despite practice: The role of task experience in preschoolers recall predictions, Journal of Experimental Child Psychology 103 (2009): 152-166.

List, J.A. Does market experience eliminate market anomalies? Quarterly Journal of Economics. 118 (2003): 41-71.

Locklear, T. S., Granger, B. B., and J. G. Veres. Evaluation of a behaviorally-based appraisal system. Journal of Managerial Issues 1(1989): 66-75.

Lyons, Richard K., Foreign exchange volume: Sound and fury signifying nothing? in Jeffrey A. Frankel, Giampaolo Galli, and Alberto Giovannini (eds.), The Microstructure of Foreign exchange Markets (University of Chicago Press, Chicago: 1996): 183-201.

MacDonald, Ronald. Expectations formation and risk in three financial markets: Surveying what the surveys say. Journal of Economic Surveys 14 (2000): 69-100.

Mahajan, J. The overconfidence effect in marketing management predictions. Journal of Marketing Research 29 (1992): 329-342.

Malmendier, U., G. Tate. Does overconfidence affect corporate investment? CEO overconfidence measures revisited, European Financial Management 11 (2005): 649-659. 
McKenzie, C. R. M., M. J. Liersch and I. Yaniv. Overconfidence in interval estimates: What does expertise buy you? Organizational Behavior and Human Decision Processes, 107 (2008): 179-191.

Meese, Richard A. and Kenneth Rogoff. Empirical exchange rate models of the seventies: Do they fit out of sample? Journal of International Economics 14 (1983): 3-24.

Menkhoff, Lukas. Short-term horizons in foreign exchange? Survey evidence from dealers and fund managers, Kyklos 54 (2001): 27-48.

Miller, D. T., and Ross, M. Self-serving biases in the attribution of causality: Fact or fiction? Psychological Bulletin, 82(1975): 213-225.

Murphy, Allan H., and Robert L. Winkler. Probability forecasting in meteorology. Journal of the American Statistical Association 79 (1984): 489-500.

Nicolson, A., Ed. Société Générale Dealers Directory 2002 (London, Société Générale).

Nofsinger, John. The Psychology of Investing, Third Edition (Prentice Hall, Englewood Cliffs, New Jersey: 2007).

Oberlechner, Thomas. Importance of technical and fundamental analysis in the European foreign exchange market. International Journal of Finance and Economics, 6 (2001): 81-93.

Oberlechner, Thomas. The Psychology of the Foreign exchange Market. (John Wiley: Chichester: 2004).

Oberlechner, Thomas, and S. Hocking. Information sources, news, and rumors in financial markets: Insights into the foreign exchange market. Journal of Economic Psychology 25 (2004): 407-424.

Odean, T. Volume, volatility, price, and profit when all traders are above average. Journal of Finance 53 (1998): 1887-1934.

Oskamp, S. Overconfidence in case-study judgments. Journal of Consulting Psychology. 29 (1965): 261-265.

Poses, R. M., R. D. Cebul. The accuracy of experienced physicians' probability estimates for patients with sore throats. Implications for decision making. Journal of the American Medical Association. 254 (1985): 925-9.

Presson, P. K., and V.A. Benassi. Illusion of control: A meta-analytic review. Journal of Social Behavior \& Personality, 11 (1996): 493-510.

Pulford, B. D. and A. M. Colman. Overconfidence: Feedback and item difficulty effects. Personality and Individual Differences 23 (1997): 125-133.

Régner, I., Hilton, D., Cabantous, L., and Vautier, S. Judmental overconfidence: One positive illusion or many. Unpublished Working paper. University of Toulouse (2004).

Roll, R. The hubris hypothesis of corporate takeovers. Journal of Business, 59 (1986): 197-216.

Scheinkman, J. A., and X. Wei. Overconfidence and speculative bubbles. Journal of Political Economy, 111 (2003): 1183-1219.

Shleifer, Andrei. Inefficient Markets: An Introduction to Behavioral Finance (Oxford, Oxford University Press: 2000). 
Sieber, J. E. Effects of decision importance on ability to generate warranted subjective uncertainty. Journal of Personality and Social Psychology, 30 (1974): 688-694.

Smith, Vernon, G. Suchanek, and A. Williams. Bubbles, crashes and endogenous expectations in experimental spot asset markets, Econometrica (1988).

Soll, J. B. Determinants of overconfidence and miscalibration: The roles of random error and ecological structure. Organizational Behavior and Human Decision Processes 65 (1996): 117-137.

Soll, J. B., and J. Klayman. Overconfidence in interval estimates. Journal of Experimental Psychology: Learning, Memory, and Cognition, 30 (2004): 299-314.

Stael von Holstein, C. A. Probabilistic forecasting: An experiment related to the stock market. Organizational Behavior and Human Decision Processes 8 (1972): 139-158.

Statman, Meir, Steven Thorley, and Keith Vorkink, Investor overconfidence and trading volume, Review of Financial Studies 19 (2006): 1531-1565.

Subrahmanyam, A. Behavioural finance: A review and synthesis. European Financial Management, 14 (2008): 12-29.

Svenson, Ola. Are we all less risky and more skillful than our fellow drivers? Acta Psychologica 47 (1981): 143-148.

Taylor, Mark, and Helen Allen. The use of technical analysis in the foreign exchange market," Journal of International Money and Finance 11 (1992): 304-314.

Taylor, Shelley E., and Jonathan D. Brown. Illusion and well-being: A social psychological perspective on mental health, Psychological Bulletin 103 (1988): 193-210.

Törngren, G., and H. Montgomery. Worse than chance? Performance and confidence among professionals and laypeople in the stock market. Journal of Behavioral Finance 5 (2004): 148153.

Trivers, R. Social Evolution (Benjamin/Cummings, Menlo Park: 1985).

van de Venter, G., and D. Michayluk. An insight into overconfidence in the forecasting abilities of financial advisors. Australian Journal of Management, 32 (2008): 545-557.

Wang, Albert F. Overconfidence, investor sentiment, and evolution. Journal of Financial Intermediation, 10 (2001): 138-170.

West, R. F. and K. E. Stanovich. The domain specificity and generality of overconfidence: Individual differences in performance estimation bias. Psychonomic Bulletin and Review 4 (1997): 387-392.

Yates, L. Frank. Judgment and Decision Making (Prentice Hall, Englewood Cliffs, New Jersey: 1990).

Zuckerman, M. Attribution of success and failure revisited, or: The motivational bias is alive and well in attribution theory, Journal of Personality 47 (1979): 245-287 


\section{Appendix: "Top" and "Lower" Tier Foreign exchange Dealing Banks}

Top Tier: Leading North American foreign exchange dealing banks. The 26 banks in this category were defined as institutions included at least one of the following lists: (i) membership in on the New York Foreign exchange Committee in 2001 and/or 2002; (ii) the top 10 institutions of the Best Provider of foreign exchange Services Overall annual ranking published by Global Investor Magazine in March 2001 and/or March 2002; (iii) the top 10 institutions of the Global Top 50 Foreign exchange Market Companies by Estimated Market Share annual ranking published by Euromoney Magazine in May 2001; (iv) the top 10 institutions of the annual Best Bank Overall for foreign exchange Dealing ranking published by foreign exchange Week in December 2001; (v) the top 10 institutions in the Annual Ranking of Banks' foreign exchange Revenues 2001 published by foreign exchange Week in December 2001.

North American trading floors of the resulting 26 institutions were contacted and invited to participate in the study. Twenty-one of these trading floors agreed to participate fully, resulting in an institutional participation rate of $81 \%$ of the leading market participants. Of 551 questionnaires sent to these 21 trading floors, 326 were returned, an individual questionnaire return rate of $60 \%$.

Lower Tier: Other foreign exchange dealing banks in North America. These are defined as all other foreign exchange banking institutions in the U.S. and in Canada listed in Societe Generale's Dealer Directory (Nicolson 2002). Foreign exchange traders at these institutions were sent questionnaires by mail. Of 529 questionnaires sent to banks in this group, 90 were returned, resulting in a questionnaire return rate of $17 \%$ for this group. ${ }^{14,15}$

14. The participation rate among lower tier banks is below that of the top tier banks, but still higher than the 8 percent reported from a previous survey in the U.S. foreign exchange market (Cheung and Chinn, 2001) which used a comparable mail-out procedure. 


\section{Table 1: Characteristics of Survey Respondents}

The table provides descriptive information concerning the 416 respondents to a June 2002 survey of North American currency market professionals. Note: totals do not sum to $100 \%$ for some categories because some individuals responded to multiple categories.

\begin{tabular}{lclrlr}
\hline \multicolumn{2}{c}{ Location } & \multicolumn{2}{c}{ Product } & \multicolumn{2}{c}{ Function } \\
\hline New York City & $53 \%$ & Spot & $73 \%$ & Interbank Trader & $59 \%$ \\
U.S. non-NYC & $33 \%$ & Forward & $33 \%$ & Salesperson & $32 \%$ \\
Canada & $14 \%$ & Derivatives & $23 \%$ & Proprietary Trader & $20 \%$ \\
& & Money Market & $6 \%$ & & \\
\multicolumn{1}{c}{ Rank } & \multicolumn{2}{c}{ Age } & \multicolumn{2}{c}{ Currency Focus } \\
\hline Treas./Hd Trader & $12 \%$ & Over 41 & $30 \%$ & EUR/USD & $61 \%$ \\
Senior Trader & $75 \%$ & $36-40$ & $27 \%$ & USD/JPY & $42 \%$ \\
Junior Trader & $12 \%$ & $31-35$ & $27 \%$ & USD/CAD & $39 \%$ \\
Trainee & $1 \%$ & $26-30$ & $13 \%$ & GDP/USD & $30 \%$ \\
& & Less than 25 & $3 \%$ & USD/CHF & $20 \%$ \\
& & & & USD vs Other & $20 \%$ \\
& & & & EUR/JPY & $11 \%$ \\
& & & & EUR/GBP & $11 \%$ \\
& & & EUR/CHF & $8 \%$ \\
& & & & EUR vs Other & $10 \%$ \\
\hline
\end{tabular}


Table 2: Point Forecasts Less Accurate Than No-Change Forecast

The table shows that exchange-rate forecasts of North American currency market professionals were generally less accurate than the no-change forecast, with accuracy measured as root mean squared error (RMSE) *100. Point forecasts for exchange rates on December 1, 2002 and June 1, 2003 were submitted by 375 North American currency market professionals as part of a survey distributed in June of 2002.

\begin{tabular}{|c|c|c|c|c|c|}
\hline \multicolumn{6}{|l|}{ A. Proprietary Traders Only } \\
\hline \multicolumn{6}{|l|}{ Forecast for December 1} \\
\hline RMSE, No-Change (\%) & 1.41 & 2.72 & 1.16 & 1.21 & 1.76 \\
\hline RMSE, Prop. Traders (\%) & 5.06 & 5.42 & 3.17 & 5.09 & 3.74 \\
\hline t-statistic vs. No-Change & $(7.21)$ & $(3.79)$ & $(4.11)$ & $(4.45)$ & $(3.16)$ \\
\hline \multicolumn{6}{|l|}{ Forecast for June 1} \\
\hline RMSE, No-Change (\%) & 18.01 & 1.87 & 1.96 & 13.74 & 13.11 \\
\hline RMSE, Prop. Traders (\%) & 18.76 & 10.33 & 5.31 & 15.00 & 12.60 \\
\hline t-statistic vs. No-Change & $(0.92)$ & $(3.38)$ & $(5.32)$ & $(1.64)$ & $(-0.76)$ \\
\hline \multicolumn{6}{|l|}{ Sales and Interbank Traders } \\
\hline Forecast for December 1, RMSE & 4.72 & 5.59 & 3.25 & 4.30 & 3.80 \\
\hline t-statistic vs. Prop. Traders & $(0.79)$ & $(-0.28)$ & $(-0.32)$ & $(1.27)$ & $(-0.14)$ \\
\hline Forecast for June 1, RMSE & 18.84 & 7.12 & 5.05 & 15.03 & 11.07 \\
\hline t-statistic vs. Prop. Traders & $(-0.09)$ & $(1.81)$ & $(0.43)$ & $(-0.04)$ & $(2.05)$ \\
\hline \multicolumn{6}{|l|}{ B. All Traders } \\
\hline \multicolumn{6}{|l|}{ Forecast for December 1} \\
\hline RMSE, No-Change (\%) & 1.31 & 3.34 & 1.24 & 1.24 & 2.05 \\
\hline RMSE, All Traders (\%) & 4.83 & 5.54 & 3.22 & 4.56 & 3.78 \\
\hline t-statistic vs. No-Change & $(10.6)$ & $(6.84)$ & $(8.77)$ & $(8.98)$ & $(8.00)$ \\
\hline \multicolumn{6}{|l|}{ Forecast for June 1} \\
\hline RMSE, No-Change (\%) & 17.70 & 1.89 & 1.25 & 13.37 & 12.37 \\
\hline RMSE, All Traders (\%) & 18.81 & 8.26 & 5.13 & 15.02 & 11.58 \\
\hline t-statistic vs. No-Change & $(2.70)$ & $(6.38)$ & $(8.12)$ & $(4.18)$ & $(-2.70)$ \\
\hline \multicolumn{6}{|l|}{ C. Top Tier Banks Only (all traders) } \\
\hline \multicolumn{6}{|l|}{ Forecast for December 1} \\
\hline RMSE, No-Change (\%) & 1.37 & 3.46 & 1.09 & 1.36 & 1.93 \\
\hline RMSE, Top Tier (\%) & 4.84 & 5.50 & 3.23 & 4.39 & 3.62 \\
\hline t-statistic vs. No-Change & $(8.96)$ & $(5.94)$ & $(8.00)$ & $(9.95)$ & $(10.29)$ \\
\hline \multicolumn{6}{|l|}{ Forecast for June 1} \\
\hline RMSE, No-Change (\%) & 17.66 & 1.91 & 1.09 & 13.30 & 12.56 \\
\hline RMSE, Top Tier (\%) & 18.63 & 7.72 & 5.13 & 14.88 & 11.65 \\
\hline t-statistic vs. No-Change & $(2.05)$ & $(5.13)$ & $(6.67)$ & $(3.61)$ & $(-2.62)$ \\
\hline \multicolumn{6}{|c|}{ D. Lower Tier Banks Only (all traders) } \\
\hline Forecast for December 1, RMSE & 4.77 & 5.68 & 3.20 & 5.12 & 4.30 \\
\hline t-statistic vs. Top Tier & $(0.15$ & $(-0.26)$ & $(0.07)$ & $(-0.90)$ & $(-1.11)$ \\
\hline Forecast for June 1, RMSE & 19.41 & 9.92 & 5.14 & 15.51 & 11.33 \\
\hline t-statistic vs. Top Tier & $(-0.83)$ & $(-1.43)$ & $(-0.02)$ & $(-0.67)$ & $(0.57)$ \\
\hline
\end{tabular}




\section{Table 3: Confidence Intervals are Too Narrow}

Ninety-percent confidence intervals for exchange rates on December 1, 2002 and June 1, 2003 were submitted by 375 North American currency market professionals in response to a survey distributed in June of 2002. Panel A shows the share of all confidence intervals that exclude the realized exchange rate. Under the null hypothesis of rationality and independence the true fraction would be ten percent. For all traders we have on average 323 observations $(\min =300$, $\max =349)$. For proprietary traders we have on average 68 observations (min. $=64, \max =71$ ).

Panels B and C compare the proportionate width of the confidence intervals to an objective econometric estimate of the proper width, specifically the ninety-percent confidence interval constructed from GARCH volatility estimates ending in the month each forecast was compiled. Exchange-rate data from Datastream. Under the null hypothesis of rationality and independence, the true fraction is 50 percent, so statistical significance is calculated using the binomial distribution with $p=0.5$. Significance at the ten percent level indicated by *. Significance at the five percent level indicated by **. In Panel B, statistical significance is below 0.0001 in each case.

\begin{tabular}{|c|c|c|c|c|c|c|}
\hline & Average & EUR & JPY & GBP & CHF & CAD \\
\hline \multicolumn{7}{|c|}{ A. Share of raw confidence intervals excluding realized exchange rates } \\
\hline \multicolumn{7}{|c|}{ Proprietary traders } \\
\hline December 1 Forecast & 35.2 & 35.2 & 35.7 & 25.4 & 35.9 & 43.9 \\
\hline June 1 Forecast & 70.5 & 87.9 & 47.7 & 43.8 & 82.0 & 92.1 \\
\hline \multicolumn{7}{|c|}{ All traders } \\
\hline December 1 Forecast & 39.3 & 29.3 & 45.1 & 33.7 & 34.0 & 54.7 \\
\hline June 1 Forecast & 75.6 & 94.6 & 48.5 & 45.9 & 93.8 & 95.8 \\
\hline \multicolumn{7}{|c|}{ B. Percent of intervals narrower than implied by econometric estimates } \\
\hline \multicolumn{7}{|c|}{ Proprietary traders } \\
\hline December 1 Forecast & 96.8 & $98.3 * *$ & $98.3 * *$ & $99.4 * *$ & $99.1 * *$ & $88.9 *$ \\
\hline June 1 Forecast & 99.1 & $99.7 * *$ & $99.4 * *$ & $99.4 * *$ & $99.0 * *$ & $97.8 * *$ \\
\hline \multicolumn{7}{|c|}{ All traders } \\
\hline December 1 Forecast & 91.1 & $93.0 * *$ & $94.3 * *$ & $91.0 * *$ & $96.9 * *$ & $80.3 * *$ \\
\hline June 1 Forecast & 86.7 & $70.4 * *$ & $100.0 * *$ & $98.5 * *$ & $89.1 * *$ & $75.8 * *$ \\
\hline \multicolumn{7}{|c|}{ C. Top-tier banks (all traders): Percent of intervals narrower than implied by econometric estimates } \\
\hline \multicolumn{7}{|c|}{ All traders at top-tier banks } \\
\hline December 1 Forecast & 96.3 & $87.1 * *$ & $98.9 * *$ & $98.1 * *$ & $99.2 * *$ & $98.2 * *$ \\
\hline June 1 Forecast & 92.3 & $82.4 * *$ & $98.9 * *$ & $99.6 * *$ & $96.0 * *$ & $82.4 * *$ \\
\hline
\end{tabular}




\section{Table 4: Bootstrap Tests of Miscalibration}

Table shows that the tendency for currency market professionals to overestimate the precision of their exchange-rate forecasts is statistically significant. Ninety-percent confidence intervals for exchange rates on December 1, 2002 and June 1, 2003 were submitted by 375 North American currency market professionals in response to a survey distributed in June of 2002. The first row of the table shows the share of confidence intervals submitted in July 2002 that fall short of a GARCH-estimated true confidence interval, and the marginal significance of that share. The marginal significance comes from a bootstrap test of the joint null hypothesis that (1) participants' confidence interval estimates are unbiased and (2) they are uncorrelated with the true confidence interval.

\begin{tabular}{|c|c|c|c|c|c|}
\hline & EUR & JPY & GBP & CHF & CAD \\
\hline December 1 Forecast & & & & & \\
\hline Completed in July & 99.7 & 99.7 & 91.7 & 90.9 & 91.7 \\
& $(0.002)$ & $(0.000)$ & $(0.199)$ & $(0.093)$ & $(0.010)$ \\
\hline Completed in September & 99.4 & 99.7 & 100.0 & 100.0 & 99.1 \\
& $(0.013)$ & $(0.037)$ & $(0.016)$ & $(0.002)$ & $(0.000)$ \\
\hline June 1 Forecast & & & & & \\
\hline Completed in July & 75.0 & 100.0 & 100.0 & 90.9 & 90.9 \\
& $(0.131)$ & $(0.304)$ & $(0.000)$ & $(0.000)$ & $(0.156)$ \\
\hline Completed in September & 100.0 & 100.0 & 100.0 & 90.0 & 60.0 \\
& $(0.304)$ & $(0.033)$ & $(0.029)$ & $(0.295)$ & $(0.471)$ \\
\hline
\end{tabular}




\section{Table 5: Most Traders Rate Themselves Professionally Above-Average}

The table shows that North American currency market professionals tend to rate themselves as "better than average." Self-assessments of personal success were submitted by 401 individuals as part of a survey distributed in June of 2002. Participants were asked to rate their own professional success on a scale of $1=$ far below average to $7=$ far above average, with $4=$ average. "Top Tier" traders worked for "Top Tier" banks, meaning banks singled out for excellent by various market sources (see Appendix 1 for further details).

\begin{tabular}{lccc}
\hline & All Traders & Top Tier Banks & Other Banks \\
\hline $\begin{array}{l}\text { Average Self-Rating } \\
\text { (Standard Error) }\end{array}$ & 5.06 & 5.20 & 4.86 \\
Share Above Average $\mathbf{( 5 , 6 , 7 )}$ & $(0.05)$ & $(0.06)$ & $(0.11)$ \\
Share Below Average (1, 2, 3) & 73.6 & 74.9 & 68.9 \\
Number of Participants & 5.4 & 4.5 & 8.9 \\
\hline
\end{tabular}


Table 6: Bootstrap Tests of Overconfidence on Self-Assessments

The table shows that the tendency of North American currency market professionals to rate themselves as "better than average" is statistically significantly different from perfect rationality. Self-assessments of personal success were submitted by 416 North American currency market professionals as part of a survey distributed in June of 2002. Survey participants were asked to rate their own professional success on a scale of $1=$ far below average to $7=$ far above average, with $4=$ average. Their superiors were asked to rate them on the same scale, with respect to three dimensions of success: Trading Profits, Trading Potential, and Overall Contribution.

This table presents results of a bootstrap test of the hypothesis that the participants are overconfident, on average, as suggested by the high share of participants rating themselves above average and the small share rating themselves below average. The null hypothesis is that the participants are not overconfident. The statistical significance of the observed shares was found by calculating the distribution of shares that would have been observed for 1,000 sets of $n$ traders had the true distribution of success ratings been represented by the ratings submitted by superiors, where $n$ is the number of individuals with a self-rating and a complete set of ratings by their superior within a given rank-responsibility combination. This should represent the distribution of these shares under the null, for that group. The table shows the observed share and its marginal significance. Values of 0.000 indicate that the most extreme simulated share was less extreme than the observed share.

\begin{tabular}{|c|c|c|c|c|}
\hline & \multirow{2}{*}{$\begin{array}{c}\text { Observed } \\
\text { Share }\end{array}$} & \multicolumn{3}{|c|}{ Bootstrapped Marginal Significance Levels } \\
\hline & & $\begin{array}{c}\text { Overall } \\
\text { Contribution }\end{array}$ & Profitability & $\begin{array}{l}\text { Trading } \\
\text { Potential }\end{array}$ \\
\hline \multicolumn{5}{|l|}{ Senior Interbank Traders } \\
\hline Above Average $(5,6,7)$ & 77.5 & 0.000 & 0.000 & 0.003 \\
\hline Below Average $(1,2,3)$ & 5.6 & 0.000 & 0.000 & 0.003 \\
\hline \multicolumn{5}{|l|}{ Senior Salespersons } \\
\hline Above Average $(5,6,7)$ & 76.7 & 0.009 & 0.000 & 0.014 \\
\hline Below Average $(1,2,3)$ & 5.6 & 0.001 & 0.001 & 0.000 \\
\hline
\end{tabular}




\section{Table 7: Overconfidence Unrelated to Experience}

The table shows average overconfidence for dealers of different levels of experience. Calibration is measured with respect to ninety-percent confidence intervals for exchange rates on December 1, 2002 and June 1, 2003, submitted by 375 North American currency market professionals in response to a survey distributed in June of 2002. Miscalibration is the average proportionate gap between the width of a trader's confidence intervals and the horizon-appropriate widths based on GARCH estimates of conditional volatility. For perfectly calibrated individuals, "miscalibration" equals zero. Hubris measures are based on assessments of the dealers' personal success submitted. Survey participants were asked to rate their own professional success on a scale of $1=$ far below average to $7=$ far above average, with $4=$ average. Their superiors were asked to rate them on the same scale. The hubris measure itself is the difference between the superior's rating and the individual's own rating. "Hubris share" represents measured hubris as a fraction of the gap between seven, the highest possible rating, and the superior's average rating for a given group. ${ }^{16}$

\section{A: Miscalibration, All Traders}

\begin{tabular}{|c|c|c|c|c|}
\hline $\begin{array}{r}\text { Experience }= \\
\text { Years Trading }\end{array}$ & $\begin{array}{l}0-8 \\
\text { Years } \\
\end{array}$ & $\begin{array}{l}9-14 \\
\text { Years }\end{array}$ & $\begin{array}{c}15+ \\
\text { Years }\end{array}$ & \\
\hline Miscalibration & 0.46 & 0.47 & 0.50 & \\
\hline$t$-statistic & 19.76 & 24.07 & 9.92 & \\
\hline Number obs. & 106 & 102 & 107 & \\
\hline \multicolumn{5}{|c|}{$t$-statistics for differences across groups } \\
\hline $0-8$ yrs vs. ... & & -0.25 & -0.79 & \\
\hline $9-14$ yrs vs. ... & & & -0.68 & \\
\hline Experience $=$ Age & $\begin{array}{c}30 \text { Years \& } \\
\text { Under }\end{array}$ & $\begin{array}{l}31 \text { to } 35 \\
\text { Years }\end{array}$ & $\begin{array}{l}36 \text { to } 40 \\
\text { Years }\end{array}$ & $\begin{array}{c}41+ \\
\text { Years }\end{array}$ \\
\hline Miscalibration & 0.46 & 0.46 & 0.51 & 0.46 \\
\hline$t$-statistic & 13.03 & 22.66 & 8.97 & 24.42 \\
\hline Number obs. & 56 & 96 & 95 & 103 \\
\hline \multicolumn{5}{|c|}{$t$-statistics for differences across groups } \\
\hline Under 30 yrs vs. ... & & 0.07 & -0.77 & -0.09 \\
\hline $31-35$ yrs vs. ... & & & -0.90 & -0.24 \\
\hline $36-40$ yrs vs. ... & & & & 0.80 \\
\hline Experience $=$ Rank & $\begin{array}{c}\text { Trainees \& } \\
\text { Junior Trad- } \\
\text { er }\end{array}$ & $\begin{array}{l}\text { Senior } \\
\text { Trader }\end{array}$ & $\begin{array}{l}\text { Head Traders } \\
\text { \& Treasurers }\end{array}$ & \\
\hline Miscalibration & 0.42 & 0.47 & 0.62 & \\
\hline$t$-statistic & 11.58 & 37.62 & 4.52 & \\
\hline Number obs. & 49 & 257 & 38 & \\
\hline \multicolumn{5}{|c|}{$t$-statistics for differences across groups } \\
\hline Trainee \& Jr. Trader vs. ... & & 1.41 & 1.43 & \\
\hline Senior Trader vs. ... & & & 1.08 & \\
\hline
\end{tabular}

\footnotetext{
${ }^{16}$ Suppose a superior rated a group 4.5 on average, in which case the gap would be $2.4=7-4.5$. If measured hubris for that group were 0.5 , then the Hubris share would be $0.5 / 2.5=0.20$.
} 
Table 7B: Hubris, All Traders

\begin{tabular}{|c|c|c|c|c|}
\hline $\begin{array}{r}\text { Experience }= \\
\text { Years Trading }\end{array}$ & $\begin{array}{l}0-8 \\
\text { Years }\end{array}$ & $\begin{array}{l}9-14 \\
\text { Years }\end{array}$ & $\begin{array}{c}15+ \\
\text { Years }\end{array}$ & \\
\hline Hubris & $\mathbf{0 . 5 0}$ & 0.47 & 0.65 & \\
\hline$t$-statistic & 2.25 & 2.81 & 2.19 & \\
\hline Hubris share & 0.14 & 0.22 & 0.26 & \\
\hline Number obs. & 57 & 76 & 51 & \\
\hline \multicolumn{5}{|c|}{$t$-statistics for differences across groups } \\
\hline $0-8$ yrs vs. ... & & 0.09 & -0.40 & \\
\hline $9-14$ yrs vs.... & & & -0.51 & \\
\hline Experience $=$ Age & $\begin{array}{c}30 \text { Years \& } \\
\text { Under }\end{array}$ & $\begin{array}{l}31 \text { to } 35 \\
\text { Years }\end{array}$ & $\begin{array}{l}36 \text { to } 40 \\
\text { Years }\end{array}$ & $\begin{array}{c}41+ \\
\text { Years }\end{array}$ \\
\hline Hubris & 0.23 & 0.64 & 0.57 & 0.46 \\
\hline$t$-statistic & 0.94 & 3.70 & 2.37 & 2.06 \\
\hline Hubris share & 0.10 & 0.27 & 0.27 & 0.19 \\
\hline Number obs. & 47 & 73 & 61 & 60 \\
\hline \multicolumn{5}{|c|}{$t$-statistics for differences across groups } \\
\hline Under 30 yrs vs. ... & & -1.36 & -0.98 & -0.69 \\
\hline $31-35$ yrs vs.... & & & 0.24 & 0.64 \\
\hline $36-40$ yrs vs. ... & & & & 0.33 \\
\hline Experience $=$ Rank & $\begin{array}{c}\text { Trainees \& } \\
\text { Junior } \\
\text { Trader }\end{array}$ & $\begin{array}{l}\text { Senior } \\
\text { Trader }\end{array}$ & $\begin{array}{l}\text { Head Trad- } \\
\text { ers \& } \\
\text { Treasurers }\end{array}$ & \\
\hline Hubris & 0.41 & 0.45 & $\mathbf{1 . 1 3}$ & \\
\hline$t$-statistic & 1.52 & 3.72 & 2.06 & \\
\hline Hubris share & 0.15 & 0.18 & 0.45 & \\
\hline Number obs. & 41 & 183 & 15 & \\
\hline \multicolumn{5}{|c|}{$t$-statistics for differences across groups } \\
\hline Trainee \& Jr. Trader vs. ... & & -0.12 & -1.17 & \\
\hline Senior Trader vs. ... & & & -1.21 & \\
\hline
\end{tabular}


7C: Proprietary Traders Only

\begin{tabular}{|c|c|c|c|c|c|c|}
\hline & \multicolumn{3}{|c|}{ Miscalibration } & \multicolumn{3}{|c|}{ Hubris } \\
\hline & Sales & $\begin{array}{l}\text { Inter- } \\
\text { bank }\end{array}$ & Prop. & Sales & $\begin{array}{l}\text { Inter- } \\
\text { bank }\end{array}$ & Prop. \\
\hline Overconfidence & 0.42 & 0.49 & 0.54 & 0.16 & 0.57 & 0.92 \\
\hline$t$-statistic & 23.39 & 15.06 & 16.43 & 0.81 & 3.68 & 4.58 \\
\hline Number obs. & 108 & 174 & 64 & 72 & 127 & 39 \\
\hline \multicolumn{7}{|c|}{$t$-statistics for differences across groups } \\
\hline $\begin{array}{l}0-7 \text { yrs vs. ... } \\
8-15 \text { yrs vs.... }\end{array}$ & & -1.98 & $\begin{array}{l}-3.35 \\
-1.13\end{array}$ & & -1.65 & $\begin{array}{l}-2.70 \\
-1.35\end{array}$ \\
\hline Years Trading & $\begin{array}{c}0-8 \\
\text { Years } \\
\end{array}$ & $\begin{array}{l}9-14 \\
\text { Years } \\
\end{array}$ & $\begin{array}{c}15+ \\
\text { Years } \\
\end{array}$ & $\begin{array}{c}0-8 \\
\text { Years } \\
\end{array}$ & $\begin{array}{l}8-14 \\
\text { Years } \\
\end{array}$ & $\begin{array}{c}15+ \\
\text { Years } \\
\end{array}$ \\
\hline Overconfidence & 0.57 & 0.50 & $\mathbf{0 . 5 3}$ & 0.78 & $\mathbf{0 . 8 3}$ & 1.09 \\
\hline$t$-statistic & 8.41 & 9.03 & 10.71 & 2.50 & 3.54 & 2.21 \\
\hline Number obs. & 22 & 11 & 28 & 17 & 9 & 11 \\
\hline \multicolumn{7}{|c|}{$t$-statistics for differences across groups } \\
\hline $0-7$ yrs vs.... & & 0.83 & 0.57 & & -0.13 & -0.53 \\
\hline $8-15$ yrs vs.... & & & -0.34 & & & -0.47 \\
\hline Age & $\begin{array}{l}35 \text { Years } \\
\text { \& Under }\end{array}$ & $\bar{O}$ & & $\begin{array}{l}35 \text { Years } \\
\text { \& Under }\end{array}$ & \multicolumn{2}{|c|}{$\begin{array}{c}\text { Over } 35 \\
\text { Years }\end{array}$} \\
\hline Overconfidence & 0.55 & & & 0.94 & \multicolumn{2}{|c|}{0.90} \\
\hline$t$-statistic & 9.56 & & & 3.42 & \multicolumn{2}{|c|}{3.02} \\
\hline Number obs. & 25 & & & 19 & \multicolumn{2}{|c|}{20} \\
\hline \multicolumn{7}{|c|}{$t$-statistics for differences across groups } \\
\hline 35 \& Under vs. ..... & \multicolumn{4}{|c|}{0.27} & \multicolumn{2}{|c|}{0.09} \\
\hline
\end{tabular}


7D: Miscalibration, Top-Tier Banks Only

\begin{tabular}{|c|c|c|c|c|}
\hline $\begin{array}{c}\begin{array}{c}\text { Experience }= \\
\text { Years Trading }\end{array} \\
\end{array}$ & $\begin{array}{c}0-8 \\
\text { Years } \\
\end{array}$ & $\begin{array}{l}9-14 \\
\text { Years }\end{array}$ & $\begin{array}{c}15+ \\
\text { Years }\end{array}$ & \\
\hline Miscalibration & 0.46 & 0.46 & 0.43 & \\
\hline$t$-statistic & 18.30 & 21.74 & 18.18 & \\
\hline Number obs. & 95 & 83 & 65 & \\
\hline \multicolumn{5}{|c|}{$t$-statistics for differences across groups } \\
\hline $0-8$ yrs vs. ... & & 0.04 & 0.96 & \\
\hline $9-14$ yrs vs. ... & & & 1.01 & \\
\hline Experience $=$ Age & $\begin{array}{c}30 \text { Years \& } \\
\text { Under }\end{array}$ & $\begin{array}{l}31 \text { to } 35 \\
\text { Years } \\
\end{array}$ & $\begin{array}{l}36 \text { to } 40 \\
\text { Years }\end{array}$ & $\begin{array}{c}41+ \\
\text { Years }\end{array}$ \\
\hline Miscalibration & 0.46 & 0.46 & 0.45 & 0.46 \\
\hline$t$-statistic & 11.97 & 21.19 & 17.58 & 20.42 \\
\hline Number obs. & 51 & 83 & 66 & 72 \\
\hline \multicolumn{5}{|c|}{$t$-statistics for differences across groups } \\
\hline Under 30 yrs vs. ... & & -0.08 & 0.26 & 0.05 \\
\hline $31-35$ yrs vs. ... & & & 0.46 & 0.18 \\
\hline $36-40$ yrs vs. $\ldots$ & & & & -0.29 \\
\hline Experience $=$ Rank & $\begin{array}{c}\text { Trainees \& } \\
\text { Junior Trad- } \\
\text { er } \\
\end{array}$ & $\begin{array}{l}\text { Senior } \\
\text { Trader }\end{array}$ & $\begin{array}{l}\text { Head Traders } \\
\text { \& Treasurers }\end{array}$ & \\
\hline Miscalibration & 0.42 & 0.47 & 0.53 & \\
\hline$t$-statistic & 10.29 & 30.59 & 9.73 & \\
\hline Number obs. & 42 & 175 & 23 & \\
\hline \multicolumn{5}{|c|}{$t$-statistics for differences across groups } \\
\hline Trainee \& Jr. Trader vs & & -1.06 & -1.59 & \\
\hline Senior Trader vs. ... & & & -1.10 & \\
\hline
\end{tabular}




\section{Table 8: Miscalibration High for Experienced Dealers}

Ninety-percent confidence intervals for exchange rates on December 1, 2002 and June 1, 2003 were submitted by 375 North American currency market professionals in response to a survey distributed in June of 2002. Panel A shows the share of all confidence intervals that exclude the realized exchange rate.

Table shows the share of dealers' confidence intervals that are narrower than the correct width calculated from GARCH volatility estimates. Under the null hypothesis of perfect rationality one half of the confidence intervals would be narrower than the objective benchmark. Marginal significance for each of the ten currency-forecast-date pairs is evaluated using the binomial distribution with $n=$ the number of forecasts for that pair and $p=0.5$. The "Maximum marginal significance" is taken over those ten pairs; the "Number significant at 1\%" the number of those ten pairs significant at the 1 percent level.

\begin{tabular}{|c|c|c|c|c|c|}
\hline Years Trading & $\begin{array}{l}0-5 \\
\text { Years }\end{array}$ & $\begin{array}{l}6-10 \\
\text { Years }\end{array}$ & $\begin{array}{l}11-15 \\
\text { Years }\end{array}$ & $\begin{array}{l}16-20 \\
\text { Years }\end{array}$ & $\begin{array}{c}\text { Over 20 } \\
\text { Years }\end{array}$ \\
\hline $\begin{array}{l}\text { Percent } \\
\text { Too Narrow }\end{array}$ & 93.2 & 93.3 & 93.1 & 93.6 & 92.5 \\
\hline $\begin{array}{l}\text { Number } \\
\text { Forecasts }\end{array}$ & 569 & 683 & 931 & 404 & 654 \\
\hline $\begin{array}{l}\text { Max. Marg. Sig. } \\
\text { (Out of 10) }\end{array}$ & $3.45 E-5$ & $2.81 E-3$ & $1.10-9$ & $8.93-4$ & $3.43 E-4$ \\
\hline $\begin{array}{c}\text { Num. Sig. at 1\% } \\
\text { (Out of 10) }\end{array}$ & 10 & 10 & 10 & 10 & 10 \\
\hline Age & $\begin{array}{c}\begin{array}{c}\text { Under } 26 \\
\text { Years }\end{array} \\
\end{array}$ & $\begin{array}{c}26 \text { to 30 } \\
\text { Years } \\
\end{array}$ & $\begin{array}{c}31 \text { to } 35 \\
\text { Years } \\
\end{array}$ & $\begin{array}{c}36 \text { to } 40 \\
\text { Years } \\
\end{array}$ & $\begin{array}{c}\text { Over } 40 \\
\text { Years } \\
\end{array}$ \\
\hline $\begin{array}{l}\text { Percent } \\
\text { Too Narrow }\end{array}$ & 96.7 & 91.3 & 94.1 & 92.3 & 93.6 \\
\hline $\begin{array}{l}\text { Number } \\
\text { Forecasts }\end{array}$ & 90 & 403 & 885 & 883 & 912 \\
\hline $\begin{array}{c}\text { Max. Marg. Sig. } \\
\text { (Out of 10) }\end{array}$ & $7.87 E-2$ & $1.75 E-3$ & $2.28 E-8$ & $5.25 E-5$ & $2.24 E-6$ \\
\hline $\begin{array}{c}\text { Num. Sig. at 1\% } \\
\text { (Out of 10) }\end{array}$ & 9 & 10 & 10 & 10 & 10 \\
\hline Rank & Trainee & $\begin{array}{l}\text { Junior } \\
\text { Trader }\end{array}$ & Senior Trader & Head Trader & \\
\hline $\begin{array}{l}\text { Percent } \\
\text { Too Narrow }\end{array}$ & 90.0 & 94.0 & 93.2 & 90.9 & \\
\hline $\begin{array}{l}\text { Number } \\
\text { Forecasts }\end{array}$ & 40 & 399 & 2,358 & 373 & \\
\hline $\begin{array}{c}\text { Max. Marg. Sig. } \\
\text { (Out of 10) }\end{array}$ & 0.50 & $2.78 E-4$ & $8.87 E-16$ & $1.63 E-2$ & \\
\hline $\begin{array}{c}\text { Num. Sig. at 1\% } \\
\text { (Out of 10) }\end{array}$ & 0 & 10 & 10 & 9 & \\
\hline
\end{tabular}


Table 9: Hubris High for Experienced Dealers

Self-assessments were submitted by 416 North American currency market professionals as part of a survey distributed in June of 2002. Survey participants were asked to rate their own professional success on a scale of $1=$ far below average to $7=$ far above average, with $4=$ average. Their superiors were asked to rate them on the same scale, with respect to three dimensions of success: Overall Contribution, Trading Profits, and Trading Potential. Table shows superiors' ratings for Overall Contribution. (Results for Trading profits and Trading Potential are similar.) Table shows percent of dealers rating themselves above- or below-average and the percent of dealers rated above- or below-average by superiors.

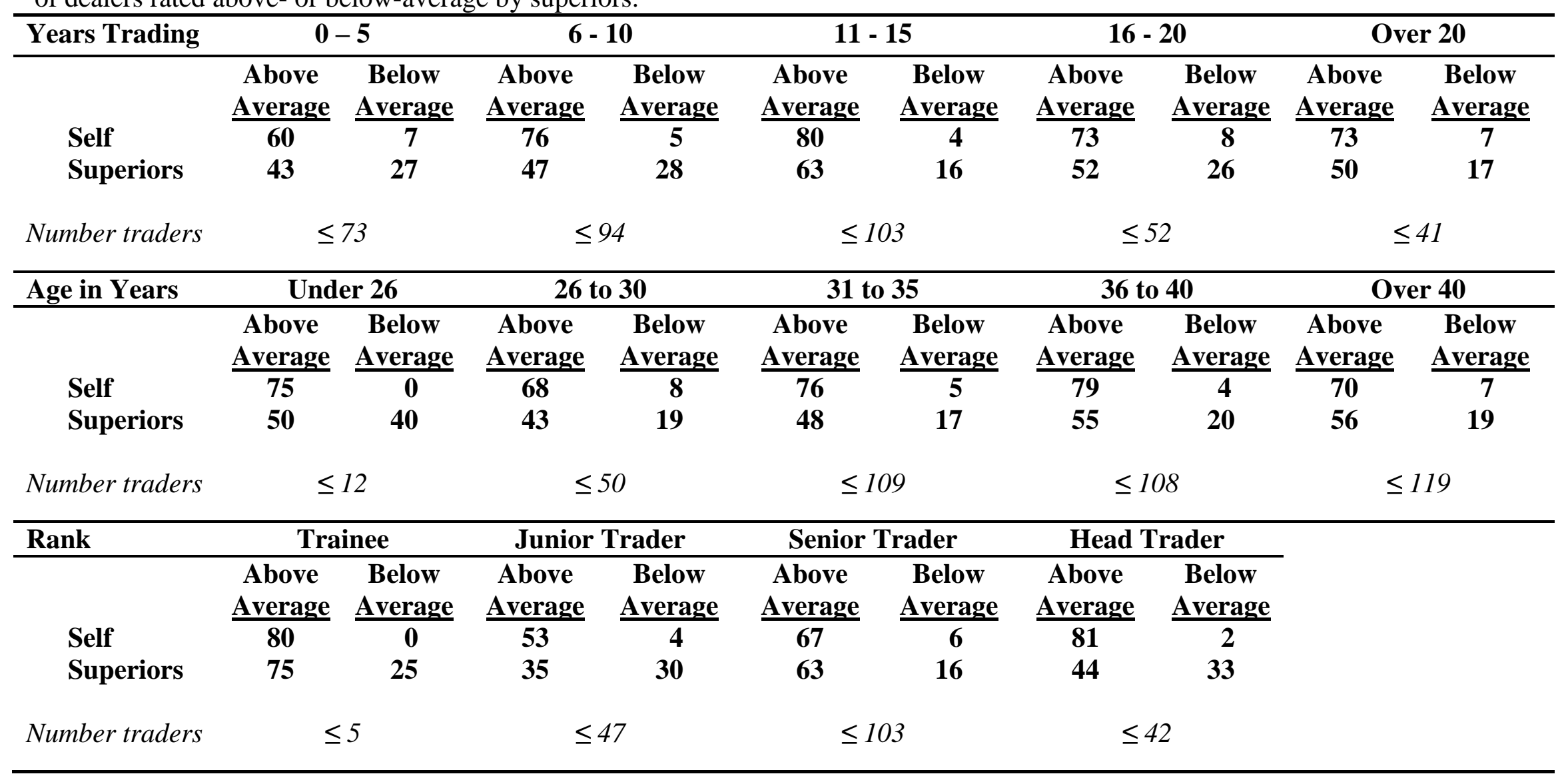

